Article

\title{
Site Effect Assessment of the Gros-Morne Hill Area in Port-au-Prince, Haiti, Part A: Geophysical-Seismological Survey Results
}

\author{
Sophia Ulysse ${ }^{1,2,3, *}$, Dominique Boisson ${ }^{1}$, Claude Prépetit ${ }^{2}$ and Hans-Balder Havenith ${ }^{3, * \text { (1) }}$ \\ Research Unit in Geosciences, Université d'Etat d'Haïti, 6112 Port-au-Prince, Haïti; dmboisson@yahoo.com \\ 2 Bureau des Mines et de l'Energie, 2174 Port-au-Prince, Haïti; claudeprepetit@hotmail.com \\ 3 Department of Geology, Liège Université, 4000 Liège, Belgium \\ * Correspondence: sophiaulysse@gmail.com (S.U.); HB.Havenith@uliege.be (H.-B.H.)
}

Received: 22 January 2018; Accepted: 19 April 2018; Published: 23 April 2018

\begin{abstract}
After the $M=7.0$ Haiti earthquake in 2010, many teams completed seismic risk studies in Port-au-Prince to better understand why this not extraordinarily strong event had induced one of the most severe earthquake disasters in history (at least in the Western World). Most highlighted the low construction quality as the main cause for the disaster, but some also pointed to possible soil and topographic amplification effects, especially in the lower and central parts of Port-au-Prince (e.g., close to the harbor). However, very detailed local studies of such site effects have not been completed yet. A Belgian-Haitian collaboration project was established in order to develop a detailed local seismic hazard study for Gros-Morne hill located in the district of Pétion-Ville, southeast of Port-au-Prince. In order to have a better understanding of the amplification on the Gros-Morne hill, in the southeastern part of Port-au-Prince, site effects were investigated by using near surface geophysical methods. The horizontal to vertical spectral ratio technique was applied to ambient vibrations and earthquake data, and multichannel analysis of surface waves and P-wave refraction tomography calculation were applied to seismic data. Standard spectral ratios were computed for the S-wave windows of the earthquake data recorded by a small temporary seismic network. Electrical resistivity tomography profiles were also performed in order to image the structure of the subsurface and detect the presence of water, if any. The spectral ratio results generally show low to medium (1.5-6) resonance amplitudes at one or several different resonance frequencies (for the same site), between 0.5 and $25 \mathrm{~Hz}$. At most of the investigated sites, the fundamental resonance frequency varies between 7 and $10 \mathrm{~Hz}$. By using the multichannel surface wave analyses of the seismic data, we were able to determine shear wave velocities ranging between 200 and $850 \mathrm{~m} / \mathrm{s}$, up to a depth of about $15-20 \mathrm{~m}$. From the refraction analysis, we were able to delineate P-waves velocities of 500 to $1500-2000 \mathrm{~m} / \mathrm{s}$ at the studied sites. The outputs were locally compared with the resistivity data from the electrical profiles. Thus, the overall data indicate a moderate site effect at Gros-Morne hill, with a great variability in site amplification distribution. Initial estimates of local site effects were made on the basis of those outputs and the earthquake recordings. Our results are finally discussed with respect to outputs and interpretations that had been published earlier for the same site. Those results only partly confirm the strong seismic amplification effects highlighted by previous papers for this hill site, which had been explained by the effects of the local topographic and soil characteristics.
\end{abstract}

Keywords: electrical and seismic measurements; ambient vibrations; earthquake recordings; topographic amplification; soil characteristics; reference site; source-path-site effects 


\section{Introduction}

Haiti is crossed by two major strike-slip faults: that of the southern peninsula and the one that transects Haiti's northern part. Between the two, there are also major reverse faults that reflect the compression component of the plate motion. Several significant earthquakes have occurred in the past and in particular along the strike-slip faults (see the map of historical seismicity in Figure 1). In the northern part, cities such as Cap-Haïtien, Port-de-Paix and Môle Saint-Nicolas, were totally destroyed by the 7 May 1842 earthquake generated along the Septentrional Fault Zone (SFZ in Figure 1); and on 23 September 1887, Mole Saint-Nicolas was nearly completely ruined by a seismic event that occurred along the same fault zone. In the southern part, the events of 1701, 1751 and 1770, probably along the Enriquillo-Plantain Garden Fault Zone (EPGFZ), severely impacted the cities of Port-au-Prince and Léogâne, and on 8 April 1860, the coast from Petit-Goave to Anse-à-Veau was affected by a moderate earthquake.

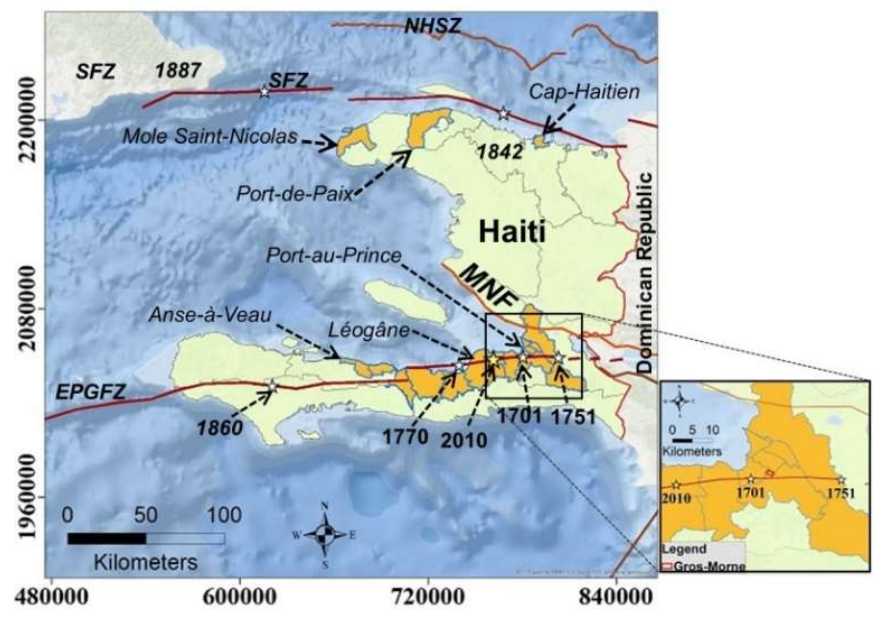

Figure 1. Map of historical seismicity of Haiti (Projection: UTM 18 N). SFZ: Septentrional Fault Zone; NHSZ = North Hispaniola Subduction Zone; EPGFZ = Enriquillo-Plantain Garden Fault Zone; MNF: Matheux-Neiba Fault. Dates indicate years of major earthquakes at the respective locations. Cities impacted by those earthquakes are indicated by orange fill. Lower right: focus on Port-au-Prince with the target zone marked by a small red rectangle.

All active faults give rise to a substantial seismic hazard in Haiti. In fact, the most recent seismic hazard maps from [1] exhibit high hazard along the Septentrional Fault Zone, the Enriquillo-Plantain Garden Fault Zone (EPGFZ), both marked by strike-slip movements, and the Matheux-Neiba Fault, marked by a thrust mechanism with a peak ground motion acceleration reaching $0.4 \mathrm{~g}$ within the target regions of our study that are located in the southern part of the country, and this for a 475-year return period (about twice the estimate made by [2]. The last results by [3] show that this hazard level could even be higher than it had been predicted by [1].

The $\mathrm{M}=7.1$ Haiti earthquake on 12 January 2010 killed more than 230,000 people, left 1.3 million homeless and caused 8-14 billion dollars in damage directly related to the event (about 100\% of the country's gross domestic product). The hypocenter of this event was located on a north dipping fault, the Léogâne fault, which is connected to the EPGFZ system, at $27 \mathrm{~km}$ to the west of Port-au-Prince. The disaster extent was firstly attributed to the proximal location of the densely-populated areas around and inside Port-au-Prince and also to the high vulnerability of many constructions [4]. However, the greatest damage was observed in hilly areas and in locations marked by the presence of thick soft layer deposits. One of the high topographical areas that suffered severe damage is the hill of Gros-Morne located in the southeastern part of the Haitian capital (see the location in Figure 2 and in Figure 3). This hill is interesting for a local seismic hazard study, not only due to the extensive damage caused primarily on its southern slope, but also due to the collapse of a famous hotel, the Hotel 
Montana, located on top of it. A series of studies have tried to explain why some zones on top of Gros-Morne hill and along the southern slope were affected by particularly severe damage during the 2010 main event (see the map in Figure 3b, modified from [5]. Additionally, multiple surface effects such as minor slides occurred (see Figure 3c) on its southern slope. Several authors have investigated the lithological and topographical site conditions in the area of Port-au-Prince. Hough et al. [5] analyzed aftershock data recorded by station HHMT installed on the Hotel Montana site with respect to station HCEA installed on hard limestone rocks in the "Massif de la Selle" in the south of Port-au-Prince (see station locations in Figure 3a). They attributed part of the amplification to topographic effects and part to soft soil amplification. To better determine the origin of this amplification, Assimaki et al. [6] reanalyzed the same dataset of recorded aftershocks and also completed numerical simulations. They presented spectral ratios for the Hotel Montana site, which they explained as being related to both topographical and soil amplification, but the amplitudes of the computed spectral ratios were larger by a factor of two than those produced by [5]. Also using the aftershocks recordings, Saint-Fleur et al. [7] combined the spectral ratios technique and numerical simulation to assess the amplification around Port-au-Prince, including the area of Hotel Montana. They highlighted a significant variability in the amplification distribution of the layers below Hotel Montana. More recently, Grelle et al. [8] proposed models computing both the topographical aggravation factor and soil amplification, which were implemented for two locations in Haiti: the station HCEA and the station HHMT. They also argued that the amplification at Hotel Montana is due to topographical and soft soil amplification. Overall, these studies are in good agreement about the resonance frequencies at the Hotel Montana site. Nevertheless, some inconsistencies remain regarding the amplification factor, the causes of the resonance frequency peaks that have been observed by several research teams and the relation between the amplification and recorded post-seismic damage. Finding those causes and relations is not a simple task as [7] have already highlighted the significant variability in soil response that is probably related to a complex subsurface structure.

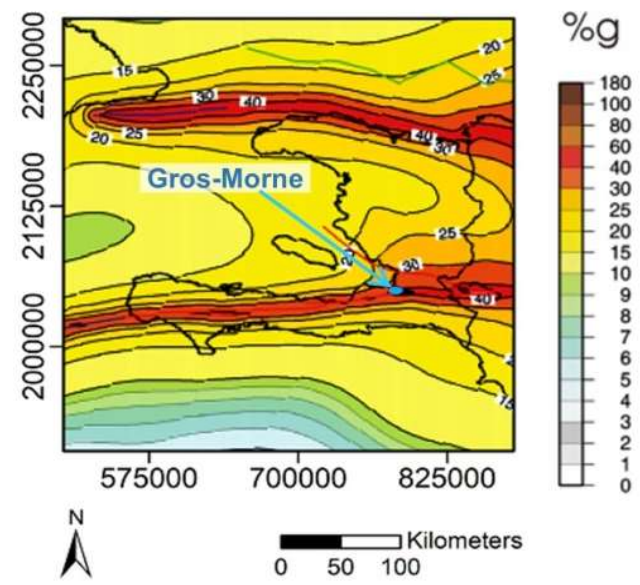

Figure 2. Seismic hazard map for Haiti with $10 \%$ of a probability of exceedance in 50 years; modified from [1]. The studied Gros-Morne hill area is outlined by a light blue ellipse.

To better apprehend the local seismic response of soils and determine the subsurface structure at the Gros-Morne site, we completed a densely integrated geophysical-seismological survey. First, we compiled geological and geotechnical information for the Gros-Morne site, and second, earthquake shaking was recorded by an array of three stations that were installed over several months in 2016-2017 in that area. Third, we performed multiple geophysical surveys. We performed five electrical profiles (processed as electrical resistivity tomography) and eighteen seismic profiles to define both P- and S-wave velocities over depth. Measured electrical resistivity data were processed in terms of 2D Electrical Resistivity Tomography (ERT). The seismic tests were essentially processed in terms of 
Multichannel Analysis of Surface Waves (MASW), but 2D P-wave seismic refraction tomography (SRT) analysis was also applied to two of them. This allowed us to determine S-wave velocity logs and 2D P-wave tomographies. These results were locally compared with the resistivity data from the electrical profiles. About one hundred single station ambient vibration measurements were recorded and analyzed in terms of Horizontal to Vertical Spectral Ratios (HVSR). These measurements provided first and foremost the local resonance frequencies, and combined with shear-wave velocity data, they enabled assessment of the thickness of the amplifying layers. To better constrain the amplification potential, we applied the Standard Spectral Ratio (SSR) technique to the earthquake data recorded by the three fixed seismological stations. From the mobile single station measurements, we produced maps of the changing resonance frequency peak (s). Finally, the overall geophysical results from our geophysical measurements compared with the outcome from previous studies helped us to understand that the ground motion at the Gros-Morne hill cannot only be explained by local site effects and that other parameters such as source and path should be implied

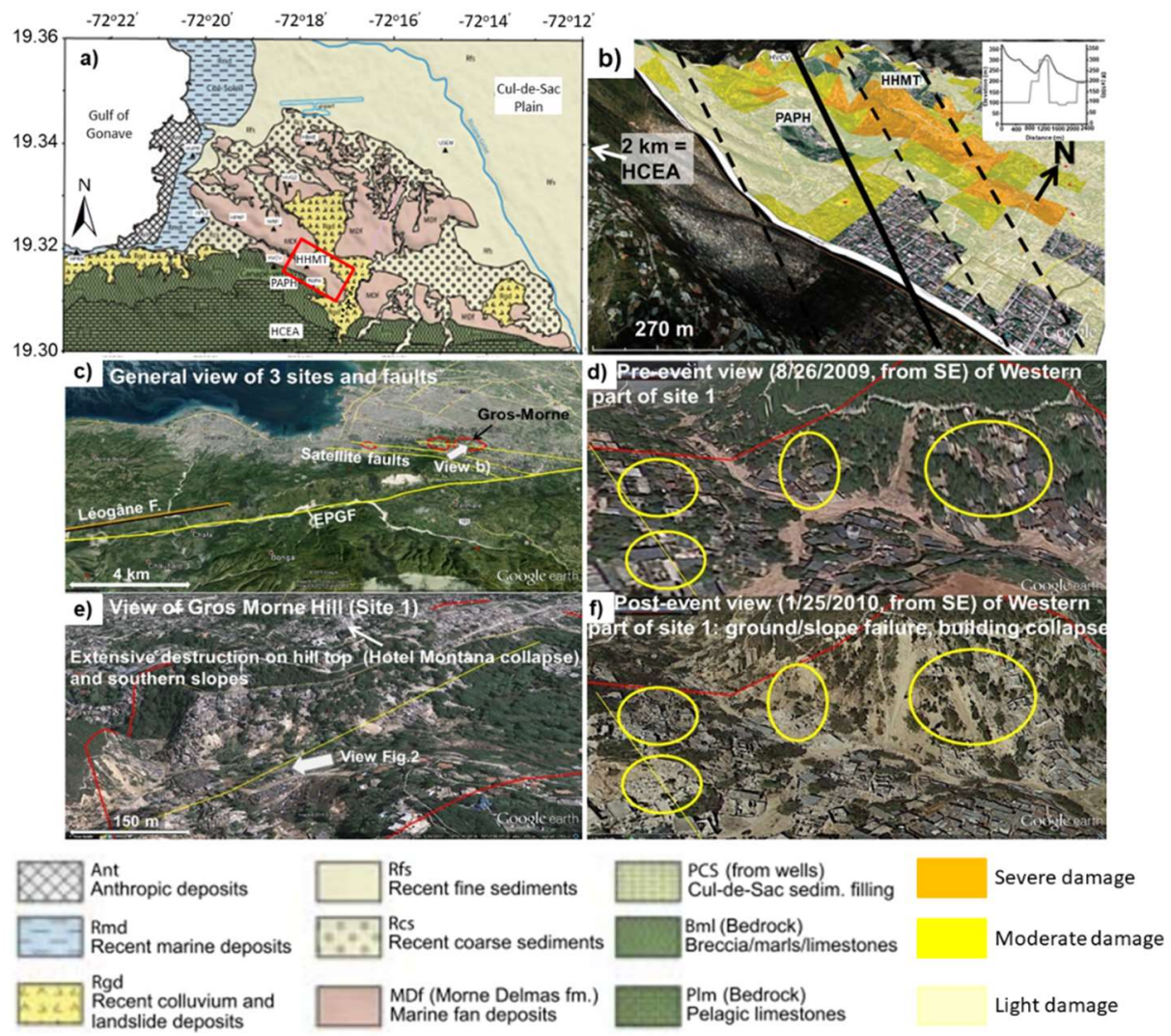

Figure 3. (a) Map modified from [5] with target area outlined by red rectangle. Location of the stations deployed after the 12 January 2010 earthquake, highlighting the locations of stations HHMT, PAPH and HCEA for which results are presented in the Discussion Section. HHMT is the Hotel Montana station located on the Morne-Delmas formation soft rocks; PAPH is located on marls, breccia and soft limestones; HCEA is located on hard pelagic limestone (from [7]). The main fault crossing the Gros-Morne-Pétion-Ville area is marked by a black line. (b) Damage distribution map presented by [5] for the Gros-Morne hill area with added fault outlines and station locations. Orange zones mark those affected by the severest damage in that area. (c) Google Earth ${ }^{\circledR}$ views of the target area with fault outlines (see Léogâne and EPGF locations according to [9] and [10]) and (e) of the investigated Gros-Morne hill near Port-au-Prince, from SW (date of image: 24 January 2010). Comparison between (d) pre- and (f) post-event view of the western part of the hill showing building collapses and slope failures and a possible link between both. 


\section{The Gros-Morne Hill: Geological and Tectonic Setting}

The Gros-Morne area is located between the southern limit of the Cul-de-sac Plain and the northern foot of the "Massif de la Selle" mountains. Its geology (see also the geological map in Figure 4) belongs to the southeastern corner of the Morne-Delmas Formation of the middle to upper Miocene according to [11] or of the middle to upper Pliocene as reported by [12]. It globally consists of marine deposits of conglomerate, sandstone, sand, silt, coarse clay, including biomicrites, marly limestones and casual limestone beds covered by quaternary conglomeratic alluvium, calcareous breccia and some unconsolidated limestone ([10] and [11]). In this framework, we performed a geological campaign, and we investigated 13 outcrops. At the ridge, two of them evidenced in the eastern ridge a soft limestone strongly weathered, which looks like a marly limestone and forming in some areas a monogenic breccia. Moreover, a drill hole carried out near Hotel Montana identified the first top $10 \mathrm{~m}$ as clayey gravel. Combined maps from $[13,14]$ and $[10]$ indicate monogenic breccia of calcareous conglomerates including fossils dating from the Pleistocene to the late Holocene for this hilltop. The rocks become softer towards the south and include more clayey materials. In some areas, those rocks are overlaid by a marly limestone layer. The southwestern slope of the hill plunges towards a ravine, which is called "Ravine Djobel" and is occupied by a small river. At the bottom of this ravine, the soils are composed of marls, locally including small calcareous pebbles, as well as conglomeratic alluvia. Around Gros-Morne hill, the tectonic activity is marked by a set of active faults for which tectonic deformations date from the middle to upper Quaternary. These faults, with a subvertical dip at the surface, belong to the series of Trans-Haitian faults and can be classified into two main systems: one is composed of sinistral-reverse $100^{\circ} \mathrm{N}-110^{\circ} \mathrm{E}$ oriented faults connected eastward of the EPGFZ, and one is represented by the $30^{\circ} \mathrm{N}-40^{\circ} \mathrm{N}$ oriented faults. Following the hydrogeological map of the Republic of Haiti by the [15], the hydrogeology of the area is mostly dominated by a carbonate aquifer. To the north, these carbonate aquifers intercalate with marl, while in the south, they are cracked and split. An important source with a mean flow higher than $1000 \mathrm{l} / \mathrm{s}$ is situated in the southeast of the area.

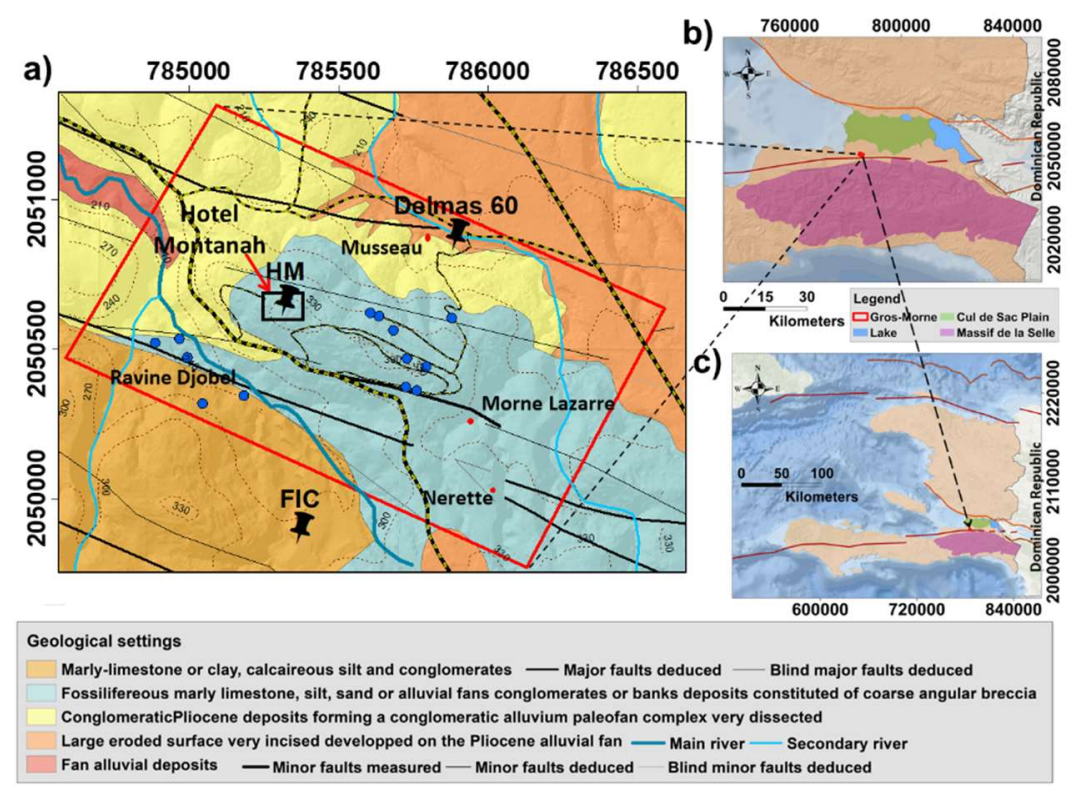

Figure 4. (a) Geological settings of the Gros-Morne area (with some geographic locations marked be red points), extracted and compiled from the $[13,14]$ and [10] geological maps; small rivers and roads are shown; blue circles are the visited outcrops' location; faults are mapped with estimated respective importance; see also the location of the three stations HM, Delmas 60 and FIC. The red rectangle in (b) delimits the location of the study area with respect to the Cul-de-Sac Plain and the "Massif de la Selle"; a general map is shown in (c). 


\section{Geophysical Investigations}

\subsection{Electrical Resistivity Tomography Measurements}

The completed Electrical Resistivity Tomography (ERT) measurements provided two-dimensional cross-sections delineating the subsurface resistivity distribution. It is a common method used for general subsurface investigations and for fault prospection in particular. Thus, it has already been applied to image the internal structure of fault zones and to detect the presence of fluids [16]. Due to the presence of many constructions on the Gros-Morne site, it was only possible to complete five ERT profiles (ERT01, ERT02, ERT03, ERT04 and ERT05), and even these were completed in very difficult conditions (see the location in Figure 5). A Terrameter resistivity meter (ABEM company instrument, Cintre, France) coupled with an acquisition system of 64 electrodes arranged along a straight profile was used. A constant spacing of $2 \mathrm{~m}$ between electrodes was used, and data were acquired according to the Wenner array configuration. All ERT profiles completed around Gros-Morne hill (see also the map in Figure 5) thus had a total length of $126 \mathrm{~m}$. Data from three ERT profiles (called NR_PE1, ML_PE1 and ML_PE2; see some of these profiles in Figure 6) carried out by the LNBTP (National Laboratory of Building and Public Works, Haiti) were also used. Those measurements were carried out with the same kind of instrument, but with a set of 32 electrodes (length of $62 \mathrm{~m}$ ).

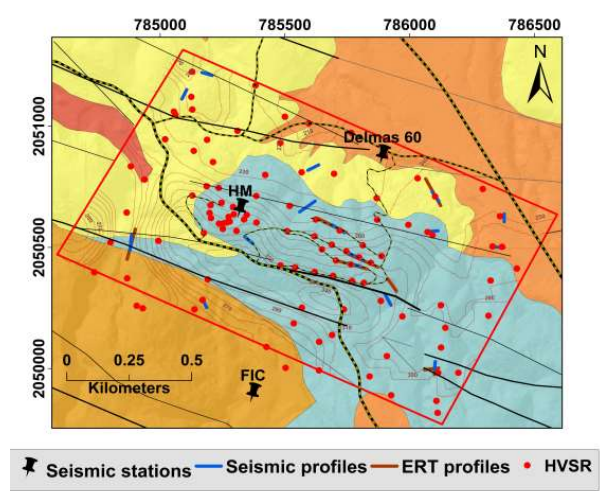

Figure 5. Geological settings of the Gros-Morne area with the location of the installed seismological stations and the geophysical measurements that were performed. HM is the station at Hotel Montana; Delmas 60 station is the one in the north; FIC is the southern station. The blue short lines are the seismic profiles, and the brown ones indicate the Electrical Resistivity Tomography (ERT) profiles. The red points are the Horizontal to Vertical Spectral Ratios (HVSR) of measurements.

\subsection{Seismic Surveys}

For the purpose of investigating the seismic properties of the subsurface, we performed 16 seismic surveys in some places of the Gros-Morne site (located in the map in Figure 5). They were named SW001, SW002 and SW004-SW017. The seismic waves were generated at the ground's surface by the impact of a 10-kg sledgehammer. The signals of the traveling waves were recorded by a set of 12 geophones with a cut-off frequency of $4.5-\mathrm{Hz}$ geophones of $4.5 \mathrm{~Hz}$ that were installed along a straight line at various distances from the source. The spread length and the near offset were selected according to the accessibility and the size of each place. The SW004-SW015 profiles extended over 44 or $55 \mathrm{~m}$ with, respectively, 4-m and 5-m geophone spacing and a near offset of either $4 \mathrm{~m}$ or $5 \mathrm{~m}$. The length of the profiles SW001 and SW002 was $33 \mathrm{~m}$ and $22 \mathrm{~m}$ with geophone spacing of $3 \mathrm{~m}$ and $2 \mathrm{~m}$, respectively. We also exploited data from a seismic survey (SW003) that was carried out by the "Imagerie des Mouvements du Sol et des Risques Naturels (IMSRN)" immediately after the earthquake in 2010 and from another seismic profile (SW018) that was realized by the LNBTP. Both were performed with 24 geophones, but the geophone spacing of the LNBTP seismic profile was $1.5 \mathrm{~m}$, giving a spread length of $34.5 \mathrm{~m}$, while a geophone spacing of $2 \mathrm{~m}$ was used for the "IMS RN" profile. For profile 
SW003, five shots, each of them including nine stacks, were considered for the refraction P-wave data: one in the center of the profile, two near the end geophones and two at 6-m offsets. The profile SW018 consisted of five shots composed of two offsets, two sources near the end geophones and another one in the center of the profile.

\subsection{HVSR Measurements}

The Horizontal to Vertical ratio method $(\mathrm{H} / \mathrm{V})$ is typically based on relatively short ambient vibration recordings at the Earth's surface (it can also be applied to earthquake recordings). By definition, HVSR represents the ratio of the average Fourier amplitude spectrum computed for the horizontal components to that of the vertical component. Initially proposed by [17], the technique became popular after the work published by [18]. This technique provides, in the case of a horizontal single soft layer overlying the bedrock, a reliable estimation of the fundamental resonance frequency of this layer $([19,20])$. However, its ability to predict a reliable amplification factor remains uncertain.

A total of 105 HVSR ambient vibration measurements were carried out over the site, with a maximum distance between two adjacent points of about $350 \mathrm{~m}$ (but most measurements were much closer to each other; see the distribution of measurements in Figure 5). Among these measurements, eight were carried out as part of the "microzonation of the city of Port-au-Prince" project, conducted by the "Bureau de Recherche Géologique et Minière (BRGM)" in 2013, in collaboration with the LNBTP and the Bureau of Mining and Energy (BME). A Tromino Engy Plus seismometer was used to provide recordings that are valid over a frequency range between 0.1 and $100 \mathrm{~Hz}$. The sampling rate selected was $128 \mathrm{~Hz}$, and the recording length was either 20 or $30 \mathrm{~min}$. For some recordings, we also used the Cityshark II instrument with a 5-s Lennartz seismometer.

\subsection{Earthquake Recordings}

The earthquake recordings were acquired over a 63-day period in the beginning of 2017, at three seismic stations located on and near Gros-Morne hill. The data were collected using three Güralp triaxial accelerometers (Güralp CMG-5TD), which were respectively installed on the northern and southern slopes (Delmas 60 and FIC) and on the top of the ridge (HM = Hotel Montana). The location of the seismic stations can be seen in Figure 5. The amplification factor at the HM site was estimated with respect to the two other sites by applying the Standard Spectral Ratio (SSR) method. This method, first applied by [21], is based on the propagation of the shear waves in the ground. It calculates, for the same recorded earthquake, the ratio between the Fourier spectrum of the S-wave window recorded at a sediment site and that measured at a reference site, which is assumed to be free of site amplification for the whole frequency range considered. This ratio can be computed separately for all three components (two horizontal and one vertical component), but it is generally applied to the average horizontal spectra. This method can be applied when the distance between the studied station and the reference station is relatively small compared to the hypocentral distance of the earthquake because the characteristics of the incident wave fields are therefore similar for both stations. The reference site is usually chosen according to the following criteria: the rock is outcropping; its average shear wave velocity down to a depth of $30 \mathrm{~m}$ is higher than $780 \mathrm{~m} / \mathrm{s}$; and it is characterized by a flat HVSR curve ([22]). It should be noted that we could not find any ideal bedrock sites (marked by a flat hard rock surface) within the target area; therefore, we will consider a "relative SSR" for the HM site with respect to the two other sites that are actually not perfect reference sites.

\section{Data Processing and Results}

\subsection{ERT Surveys}

A two-dimensional resistivity model for the subsurface was obtained by inverting the resistivity data. The inversion is based on a non-linear least-squares optimization technique and is computed using the RES2DINV software ([23]) (Version 3.57, GEOTOMO SOFTWARE SDN BHD, Penang, Malaysia). 
The software first calculates the apparent resistivity values using a forward modeling subroutine, and then iteratively, it tries to adjust the 2D apparent resistivity model with the measured resistivity values.

The investigation depth reached 15-25 m (see the results in Figure 6). The ERT04 and ERT05 profiles are located near the top of the eastern part of the ridge and are oriented parallel to the crest. The ERT01 profile was completed near the top of the northern slope; the profile ERT02 was performed near the base of the northeastern slope and the ERT03 profile along the bottom of the ravine. We also used data from three ERT profiles (ML_PE1, ML_PE2 and NR_PE1) acquired by the company IMSRN in 2012; two are shown in Figure 6.

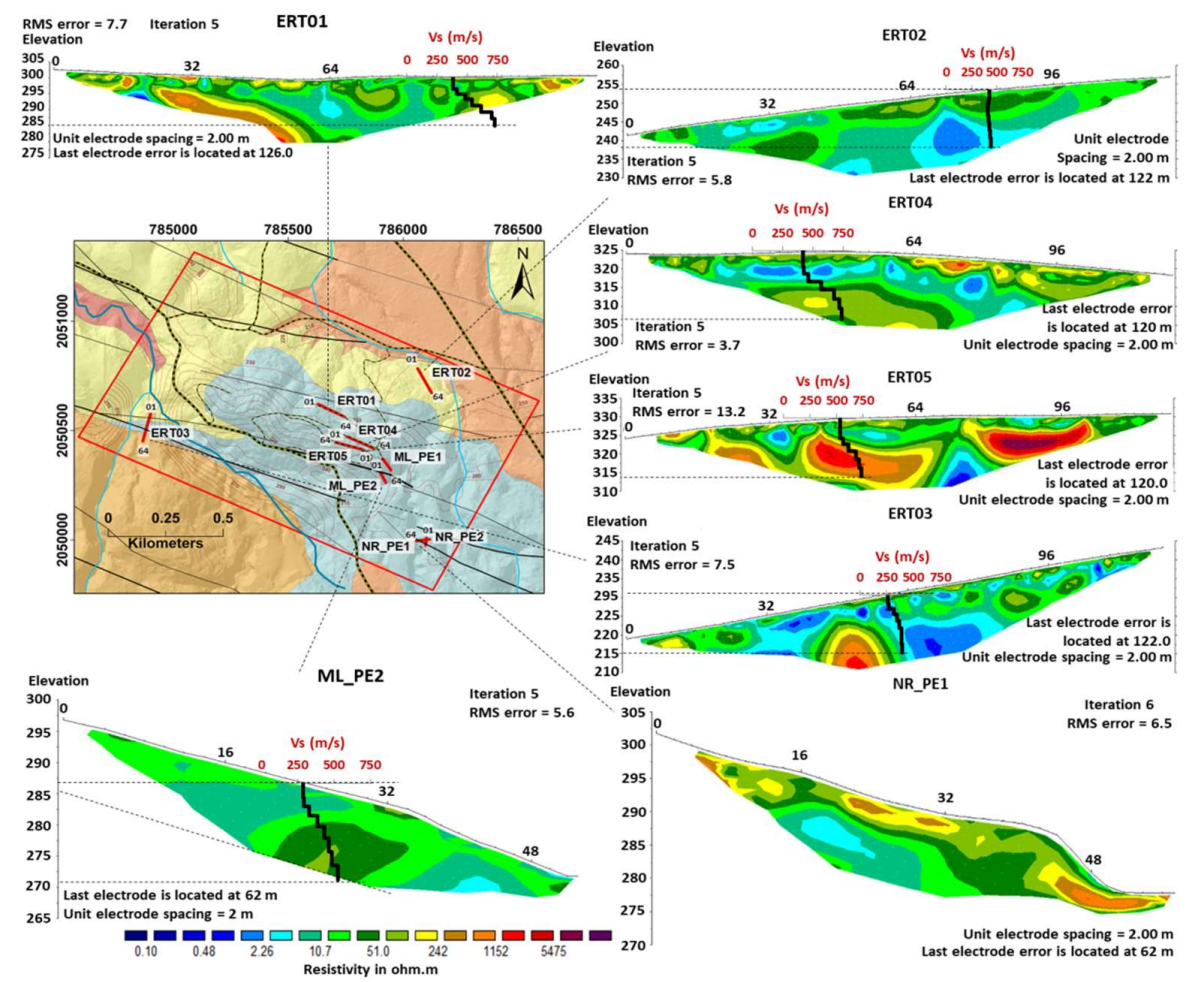

Figure 6. Location of the ERT profiles (violet lines: ERT01-ERT05 and ML_PE2 and NR_PE1) with the $2 \mathrm{D}$ electrical resistivity models. The values on the $2 \mathrm{D}$ models indicate the electrode position along the spread (in numbers: 1 is the beginning, 64 the end electrode at a position $126 \mathrm{~m}$ along the profiles ERT0x and for the ML_PE2 and NR_PE1 the last electrode is at position $64 \mathrm{~m}$ ). On each profile near Gros-Morne hill, also the nearest Vs profile is plotted, and for ML_PE2, also a comparison is made with the parallel seismic profile (in terms of P-wave velocity tomography).

Except for the crest where the resistivity values range between 1 and $5000 \Omega \mathrm{m}$, the grounds of Gros-Morne hill are quite conductive with average resistivity values of about $10-50 \Omega \mathrm{m}$. The highest values are observed on the ERT05 profile on the top of the hill, where also the shear wave values are the highest. The lowest average resistivity values were observed on profile ERT03, at the base of the hill, along the ravine, in the western corner, below the "Rue Panaméricaine" and on profile ERT02, to the north, near the "Delmas 60" area. The lowest resistivity values of less than $1 \Omega \mathrm{m}$ were obtained at the limit of the beige clayey soils of quaternary age, the conglomeratic Pliocene alluvium fan and fossiliferous marly limestone, silt and sand of coarse angular breccia along the ravine Djobel. It should be noted that both of these ERT profiles are located in the neighborhood of a river. The 1D shear wave velocity model at the ravine Djobel area also shows very low values from $200-350 \mathrm{~m} / \mathrm{s}$. Moreover, while the Vs slightly increase with depth, a decrease in the resistivity values is observed; the latter characteristic shows that both the strength of the rocks and the water content increase with 
depth. At ERT02, resistivity values also decrease with depth, while Vs values are almost constant. The ML_PE2 profile is quite homogeneous with resistivity values ranging from $10-100 \Omega \mathrm{m}$ over a depth of $13 \mathrm{~m}$. This homogeneity is also highlighted by the P-wave (Vp) tomography SW0003 cross-section that was performed in the same place. Indeed, over the first $13 \mathrm{~m}$ (the thickness also covered by the electrical profile), Vp only slightly increases with depth, from 500-900 m/s. The Vs-log shows a gradual increase in the shear wave velocity from $250-450 \mathrm{~m} / \mathrm{s}$ down to a depth of $13 \mathrm{~m}$.

\subsection{Seismic Surveys}

The seismic profiles were first analyzed with the MASW technique. This method is based on the dispersion of the Rayleigh waves that are propagating trough the ground. It is used to obtain the variation of the shear wave velocity of different layers that were crossed, particularly the $\mathrm{Vs}_{30}$. By definition, $\mathrm{Vs}_{30}$ is the shear wave velocity averaged over the first $30-\mathrm{m}$ depth and is commonly used in earthquake engineering for site characterization. In this regard, we are aware that the applied spreads of the seismic profiles (limited by the number of available geophones) do not allow us to entirely cover the first $30 \mathrm{~m}$; the investigation depth that was reached by the Vs profiles ranges between 10 and $25 \mathrm{~m}$. Therefore, we mainly used the Vs logs up to a depth of about $16 \mathrm{~m}$ (see all Vs logs in Figure 6 below). Data were processed with the Pickwin and WaveEq modules of the SeisImager software produced by Geometrics. The result is a Vs model indicating the shear-wave velocity variation over depth. By applying a Fourier transform to the signals, the software first provides a dispersion curve, which is then inverted in order to compute a Vs model.

It was possible to determine shear wave velocity profiles using the MASW processing of the seismic data, with Vs ranging between 280 and $580 \mathrm{~m} / \mathrm{s}$ near the surface and between 400 and $750 \mathrm{~m} / \mathrm{s}$ at a depth of about $15 \mathrm{~m}$. Due to the limited investigation depth, we defined a $\mathrm{Vs}_{15}$ parameter for each profile; this represents the average Vs value for the first $15 \mathrm{~m}$ (instead of $30 \mathrm{~m}$ as indicated by the commonly-used parameter $\left.\mathrm{Vs}_{30}\right)$. The lowest values $(<400 \mathrm{~m} / \mathrm{s})$ were measured along the lower parts of the hill and especially in the south at its base, within the ravine (see also the Vs log of profile SW015 in Figure 7). The grounds along the ridge and the northeastern slope are marked by higher Vs values (and are therefore considered to be more compact than in the rest of the study area). Along the hill ridge, the highest Vs values of up to $700 \mathrm{~m} / \mathrm{s}$ were obtained at a depth of $10 \mathrm{~m}$ (for SW001 and SW002 near Hotel Montana and for SW004, SW005 and SW012 in the eastern part, shown in detail in Figure 7). By interpolating the corresponding values for all profiles, we created the map presented below in Figure 7.

For a few of the seismic profiles, a 2D P-wave refraction analysis was also performed, notably for the profiles SW001 and SW003. This processing method is based on the picking of the first arrival time of the P-waves at each geophone. It provides a 2D cross-section of the distribution of the P-wave velocity resulting from the combination of multiple hodochrones. Data were processed using the Pickwin and Plotrefa modules of the SeisImager software (Version SeisImager SW, Geometrics, San Jose, CA, USA).

The analysis of two seismic profiles (SW001 and SW003) in terms of P-wave velocity tomography (profile shown in lower right part of Figure 7) shows a shallow zone marked by P-wave velocities (Vp) ranging from $400-900 \mathrm{~m} / \mathrm{s}$ and an intermediate zone with Vp between 900 and $1300 \mathrm{~m} / \mathrm{s}$ on top of a zone characterized by $\mathrm{Vp}$ higher than $1300 \mathrm{~m} / \mathrm{s}$. It should be noted that due to the short spreads, only an investigation depth of about $15 \mathrm{~m}$ was reached. By comparing both profiles, it can be seen that near the surface, SW001 presents higher Vp values than SW003, but at a depth, the latter shows slightly higher values. At the bottom part of SW003, a Vp value of up to $2100 \mathrm{~m} / \mathrm{s}$ was obtained, while in SW001, the highest values reached are below $2000 \mathrm{~m} / \mathrm{s}$. Thus, the contrast of Vp values is clearly higher along SW003 than along SW001. The stronger contrast of rock compactness along SW003 is also confirmed by the Vs log, showing a value of $300 \mathrm{~m} / \mathrm{s}$ near the surface and of $600 \mathrm{~m} / \mathrm{s}$ at a depth of around $20 \mathrm{~m}$, thus producing a ratio of two, while for SW001, the Vs ratio computed for the same depths is about $1.6(800 / 500)$. Interestingly, $\mathrm{Vs}$ at a depth of more than $10 \mathrm{~m}$ is clearly higher for 
SW001 ( $>600 \mathrm{~m} / \mathrm{s})$ than for SW003 ( 450 m/s), while for the Vp profiles, SW003 presents the larger values at this depth. The low resistivity values in the range of $2-100 \Omega \mathrm{m}$ obtained from the ML_PE2 electric profile suggest that the latter are due to the presence of water at a depth in the zone of SW003. The water content may have caused the increase in Vp values, while it does not have any influence on the Vs.
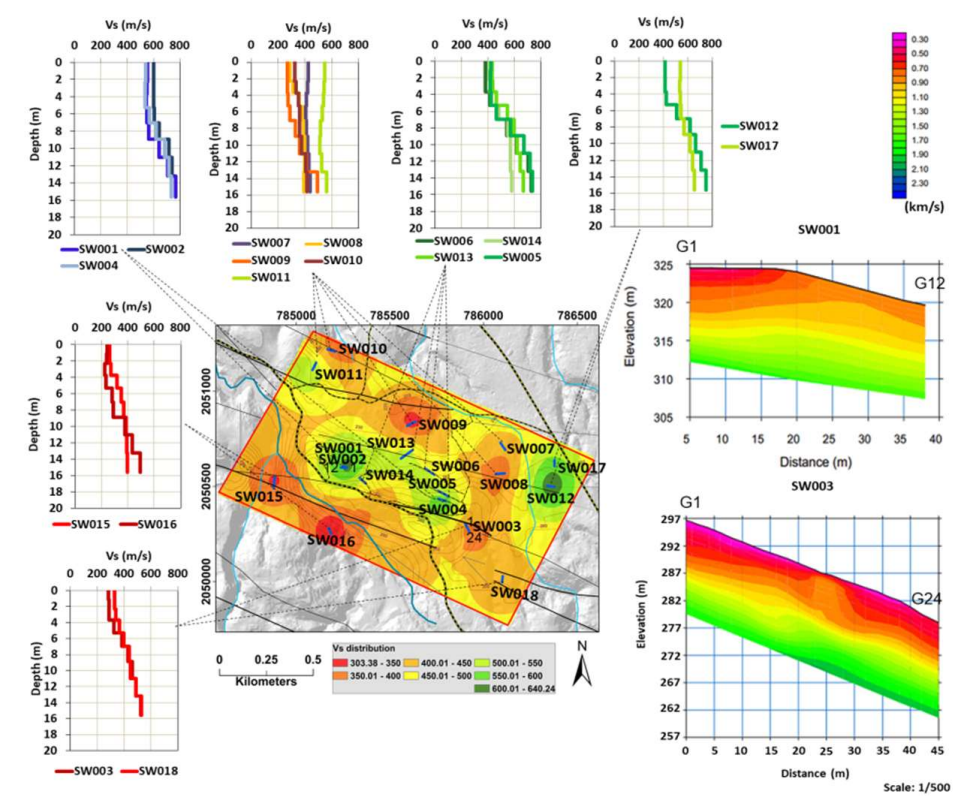

Figure 7. Left: map of distribution of shear wave velocity over the first $15 \mathrm{~m}$ of depth with locations of seismic profiles and sequence of all Vs logs obtained for the site. Right: P-wave velocity tomography profiles SW001 and SW003, with P-wave velocity color scale above.

\subsection{HVSR Results}

The processing of the ambient vibrations data was performed using the Geopsy software developed by [24]. The signal for the three components is subdivided into several time windows of a length of 20 seconds in the case of this study. For each window, the Fast Fourier Transform (FFT) is calculated, and the amplitude spectrum is smoothed by using the algorithm by [25] with a smoothing parameter equal to 40 . The analysis of these data was completed within the frequency range of 'engineering' interest between 0.25 and $25 \mathrm{~Hz}$ and taking into account the criteria of the clarity and reliability of the measured peaks recommended by the 'Site Effects Assessment using Ambient Excitations' (SESAME) project ([26]). In Figure 8 below, the locations of the selected representative HVSR recordings are shown with the indication of the interpreted fundamental resonance frequency and the peak amplitude.

On the basis of the HVSR measurements, three ambient ground motion parameters were outlined at Gros-Morne hill: (i) the fundamental resonance frequency (f0); (ii) in some cases, also a second and even third resonance frequency (f0 results are marked by colors of the circles in the map in Figure 8 below; secondary peaks are shown by small triangles in some places); (iii) the amplitude of the main peak, as well as an index that reflects the clearness of the frequency peak that we call the "sharpness of the peak". In this work, this latter parameter is defined by the ratio between the height of the peak and its width. The height of the peak is the difference between the amplitude of the frequency peak and the HVSR value at the minimum amplitude immediately before and after the peak. The width of the peak is the difference between the frequency values at the amplitude minimum immediately before the peak and the one immediately after the peak. Consequently, the higher the value of this parameter, the sharper and the clearer is the frequency peak. This methodology was adopted from [27]. Measured f0s range from $0.5-25 \mathrm{~Hz}$, noting that the fundamental frequency range of $3-5 \mathrm{~Hz}$ was only 
found in very few places. The very high f0s (15-25 Hz) are essentially at some places in the foothills, particularly near the northeastern corner where flat HVSR curves are also observed. To the southwest of the "Rue Panaméricaine", in the western corner, the f0s range from 5-12 Hz.

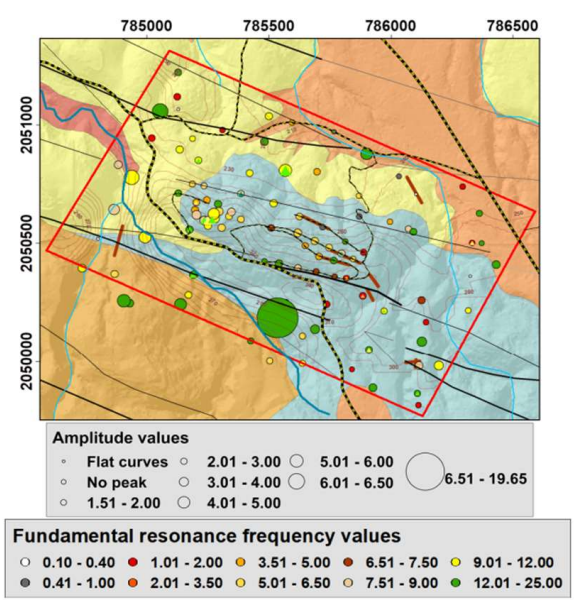

Figure 8. Distribution of the HVSR results on top of the geological map; the size of the circle indicates the amplitude level. The circle color represents the f0 values.

Observed peak amplitudes range from 1.5-7, while the peak sharpness values range from almost zero (very flat peak) to one or more (sharpness values are shown by colors in the map in Figure 9 below), considering that values of more than 0.3 can already be considered as very high (e.g., for the clear peak obtained for HVSR measurement GM_HV0092, shown in the lower right corner of Figure 9, a value of 0.25 was obtained). It should be noted that the amplitude of the peak is also represented in both maps in Figures 8 and 9 (respectively, for the $\mathrm{f} 0$ and for the peak sharpness), in terms of the size of the circle. In the next section, we also present interpolated maps of the f0 and peak amplitude to highlight the site effect distribution; the peak sharpness was not used for this purpose; we present related results in Figure 9 mainly to outline the different peaks observed over the target area.

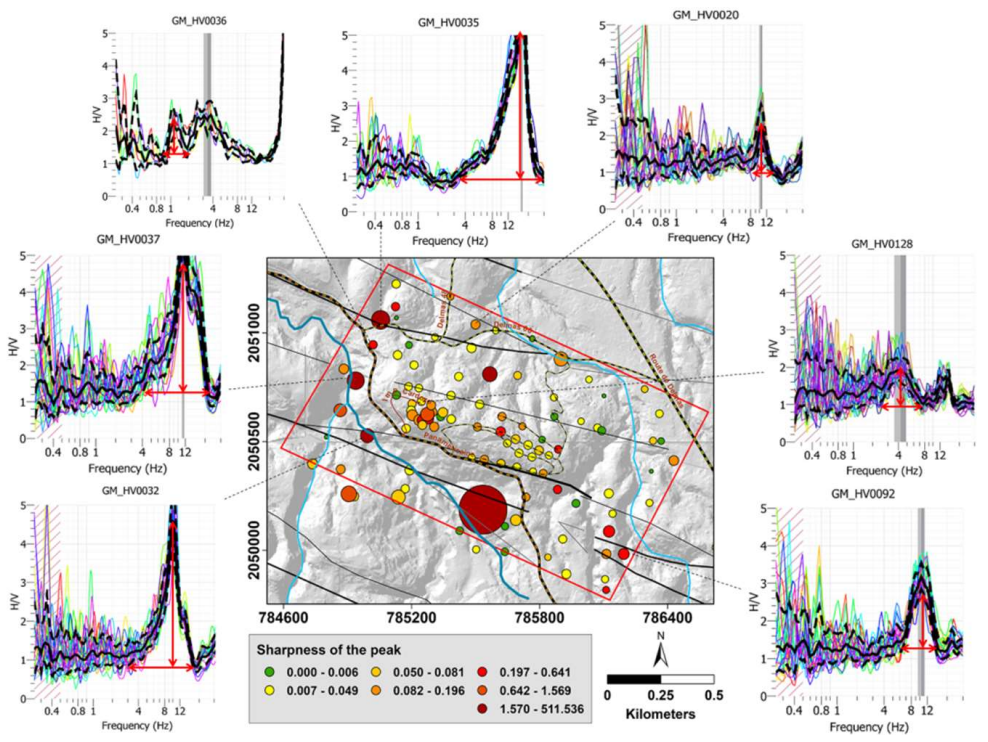

Figure 9. Distribution of the HVSR results; the size of the circle indicates the amplitude level. The color of the circle shows the sharpness of the frequency peak. For nine sites, the H/V curves are shown and the inputs for the peak sharpness calculation are outlined: the vertical and horizontal red double arrows indicate respectively the height and the width of the f0 peak. 


\subsection{Earthquake Data}

The Geopsy software was used to visualize the seismograms and identify the earthquakes. A total of 15 earthquakes were recorded at the three stations (see Figure 5 for their location) between 20 January and 23 March 2017. The epicentral distance of each event was very roughly evaluated by applying a factor of 7.5 to the P-S waves delay time, ts-tp (the factor of 7.5 was computed by using the formula: factor $=\mathrm{Vp} * \mathrm{Vs} /(\mathrm{Vp}-\mathrm{Vs})$, for $\mathrm{Vp}=6.9 \mathrm{~km} / \mathrm{s}$ and $\mathrm{Vs}=3.6 \mathrm{~km} / \mathrm{s}$; note, the authors are aware that this a very rough estimation, but for our purpose, it was sufficient as we mainly wanted to know if the epicenter is closer than $50 \mathrm{~km}$ or not). The events with an estimated epicentral distance higher than $50 \mathrm{~km}$ (practically all) were preselected for later processing. Then, the earthquakes with stronger amplitudes and larger signal lengths were chosen. Finally, only five events were selected to compute SSR. A list of all the events that were detected during the recording period is presented in the Table 1. In Figure 10, the seismograms of two selected earthquakes are presented. The analysis of the seismograms at the three stations shows, for the three components, higher amplitudes and longer duration of the signals at the FIC station and lower amplitudes at the Delmas 60 station.

Table 1. List of the 5 earthquakes that were used for the Standard Spectral Ratio (SSR) computations. The geographical coordinates (latitude and longitude) are in decimal degree WGS 1984. The epicenter location is indicated for only two events because these latter were also recorded by the USGS (U.S. Geological Survey).

\begin{tabular}{cccccccc}
\hline Julian Day & Date & Time (UTC) & Latitude & Longitude & Depth (km) & Magnitude & Location \\
\hline 43 & 12 February 2017 & $9: 33: 58$ & - & - & - & - & - \\
47 & 16 February 2017 & $12: 52: 39$ & 18.763 & 69.403 & 101.9 & 4.6 & Dominican Republic \\
55 & 24 February 2017 & $16: 10: 50$ & - & - & - & - & Dominican Republic \\
58 & 27 February 2017 & $1: 05: 26$ & 18.997 & 70.019 & 73.4 & - & - \\
63 & 4 March 2017 & $17: 14: 14$ & - & - & - & - \\
\hline
\end{tabular}

The choice of the reference site is usually done considering the seismic velocities and the characteristic amplitude of the different sites. At Gros-Morne hill, no outcropping hard rock was identified. All the shear wave velocity data that were measured over the area showed values lower than $800 \mathrm{~m} / \mathrm{s}$ (see Figure 6) over the first $15 \mathrm{~m}$. The higher S-wave velocity values were found at the crest of the hill and around the Hotel Montana where they are no greater than $750 \mathrm{~m} / \mathrm{s}$. The characteristic amplitude of the sites was estimated from the HVSR for noise Tromino data and both from the HVSR for noise and for earthquakes recorded by the seismological stations. For each station and for each file containing a selected earthquake, HVSR was calculated, on the one hand, for the signal without the earthquake (HVSRN) and, on the other hand, for the S-waves of the Earthquake recordings (HVSR_EQ). The processing is similar to the one that was applied to the single station Tromino data. However, for the HVSR_EQ, the S-wave windows were extracted from the seismograms to which a taper of 5\% had been firstly applied and a window length corresponding to the maximum duration of the S-wave signals was selected.

\subsubsection{S-Waves HVSR Results}

An ambient noise measurement was performed with the Tromino single station next to the Delmas 60 station. Below $12 \mathrm{~Hz}$, the HVSR for this recording is roughly similar to the one of the station Delmas 60 (Figure 11a). They show moderate amplitudes below $1 \mathrm{~Hz}$ and amplitudes smaller than one between 1.5 and $8 \mathrm{~Hz}$. However, for the Tromino recording, a high frequency peak is observed beyond $12 \mathrm{~Hz}$, which is not shown by the HVSR ambient vibration curves of Delmas 60 station (Figure 11b). At low frequencies ( $<3$ ), the S-wave HVSR curves (in Figure 11c), amplitude peaks of $2-3$ can be observed at $0.5 \mathrm{~Hz}$ and between 1 and $2 \mathrm{~Hz}$. As for the HVSR noise, they do not show any high frequency peak. At higher frequencies, the curve is flat. Therefore, combining results from noise and S-wave data, Delmas 60 seems to be prone to some moderate amplification at low frequencies, but is probably free from soil amplification over a frequency range between 2 and $10 \mathrm{~Hz}$. 
a)
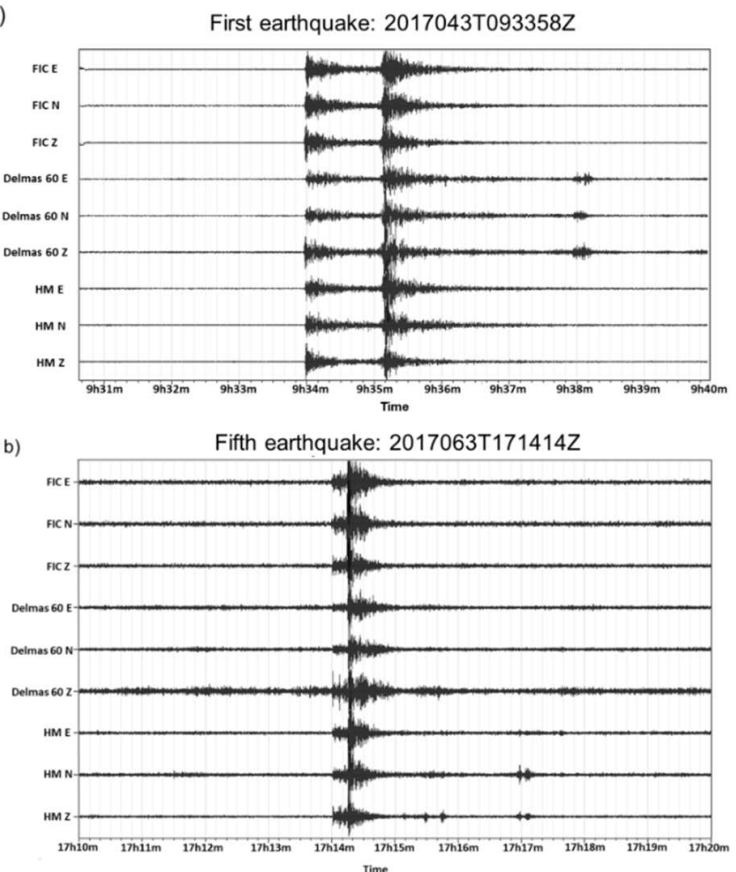

Figure 10. Seismograms (first $=E-W$, second N-S, third $=Z$ ) for two $(\mathbf{a}$ and $\mathbf{b}$ ) of the five events recorded at all three stations Delmas 60, FIC and Hotel Montana (HM) and that were selected for further analyses.
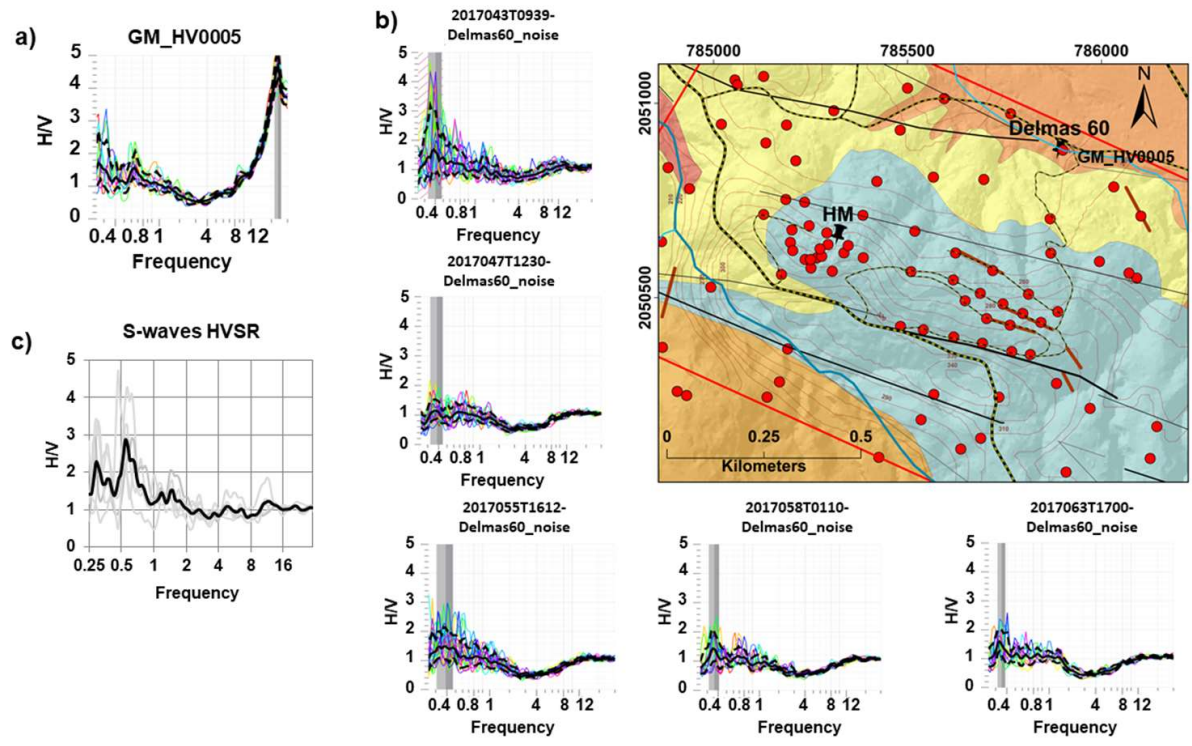

Figure 11. (a) HVSR curves from the Tromino single station (left graph) in the neighborhood of the Delmas 60 station (GM_HV0005); (b) HVSR noise curves at the seismic Delmas 60 station (central graphs); (c) single (grey curves) and mean (black curve) S-waves HVSR for the five selected earthquakes at Delmas 60 station.

The amplitude of the noise HVSR curves at the FIC station (Figure 12) is close to one. However, for most of the ambient vibration recordings, we can observe very low HVSR amplitudes between 2 and $8 \mathrm{~Hz}$. The Tromino HVSR noise curves from the recordings in the vicinity of the site are quite similar below $12 \mathrm{~Hz}$; above this frequency, higher amplitudes probably due to cultural noise appear. For the S-waves earthquake HVSR (Figure 12c), peaks are observed at $0.7 \mathrm{~Hz}$ and between 2 and $4 \mathrm{~Hz}$. Their amplitude values are of the order of two. 


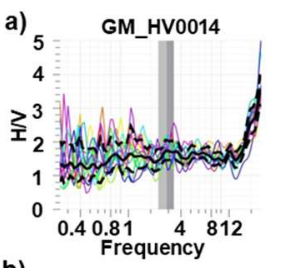

b) 201704370940-FIC_noise

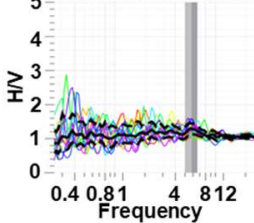

2017055T1600-FIC_noise$$
5
$$

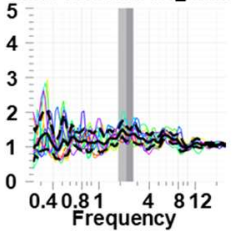

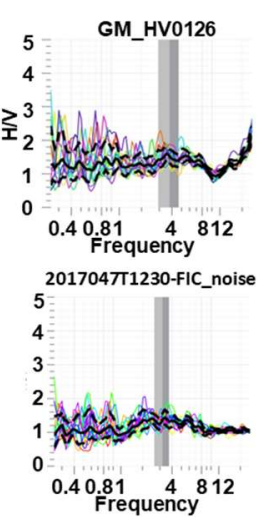

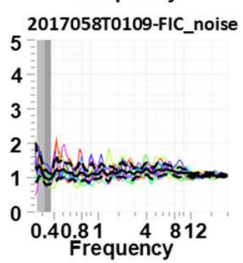

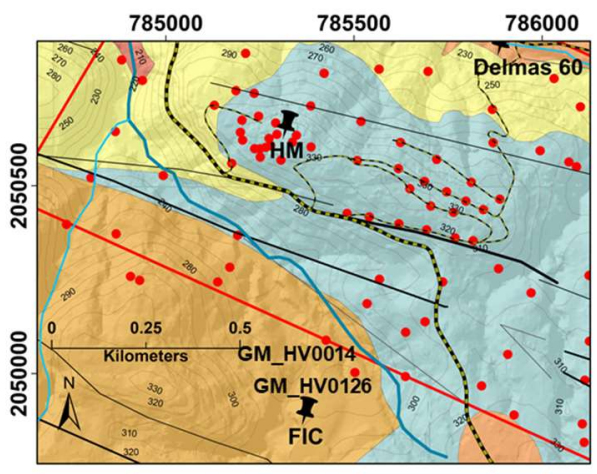
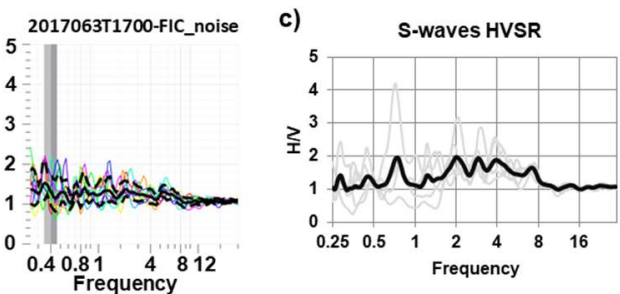

Figure 12. (a) HVSR curves from the Tromino single station in the neighborhood of the FIC seismological station (GM_HV0126 and GM_HV0014); (b) HVSR noise curves at the FIC seismic station (bottom graphs); (c) single (grey curves) and mean (black curve) S-waves HVSR for the five selected earthquakes at FIC station.

Around the HM station (Figure 13), the Tromino HVSR noise curves generally display larger amplitudes between $1.5 \mathrm{~Hz}$ and $20 \mathrm{~Hz}$. On most of the curves, broad amplitude peaks at $4-12 \mathrm{~Hz}$ can be observed. Some of them show peaks that are centered on 5-6 Hz (see measurement PAP024_01 in Figure 13a), 7-8 Hz (GM_HV0024) and 9-10 Hz (see measurements PAP024_02 and PAP024_03 in Figure 13a). In other curves (measurement GM_HV0025), narrow peaks in the same frequency ranges double or multiple resonance frequency peaks are also noticed. However, the HVSR noise curves from the HM seismological station are nearly flat. They show a weak "bump" around 3-5 Hz, with amplitudes that are much lower than those provided by the Tromino data. This $3-4-\mathrm{Hz}$ bump, with similar amplitude, was depicted by two Tromino HVSR measurements GM_HV0128 and GM_HV0129. One of both, GM_HV00129, is closer to HM station than the other Tromino recordings. This good agreement between the HVSR of these two Tromino recordings and HM station suggests that along the ridge of the hill, some places are almost free from strong impedance contrasts or from other (e.g., morphological) factors that might induce ground motion amplification. However, the sharp peaks recorded in other places along the ridge still indicate a significant impedance contrast at those areas. From the S-wave earthquake HVSR curves, moderate amplitudes of up to 2-3 are observed between 0.5 and $4.5 \mathrm{~Hz}$ (see Figure 14). The high frequency peaks above $10 \mathrm{~Hz}$ obtained for some Tromino recordings are not visible on the noise HVSR at station HM. However, as they are of limited engineering concern, they are not considered in our site effects estimations. The peaks at around $2 \mathrm{~Hz}$ pointed out by the yellow arrows in Figure 13b (and partly also visible on the HM station noise and S-waves HVSR, between 1 and $3 \mathrm{~Hz}$ ) could be due to topographic amplification. Indeed, according to the well-accepted (and proven) rule established by [28], the amplified wavelength is similar to the entire width of a hill (with free slopes to both sides of the crest), which is here equal to $700 \mathrm{~m}$. Considering the likely average Vs of 1100-1300 m/s beyond a 30-m depth for the hill material (as measured by [29]), the frequency over which the hill amplifies ground motion is in the order of 1.6-1.9 Hz. This reasoning partly fits with the results from [8], who predicted a topographical frequency peak at $2.5-3 \mathrm{~Hz}$ with an amplification factor of two. 
a)
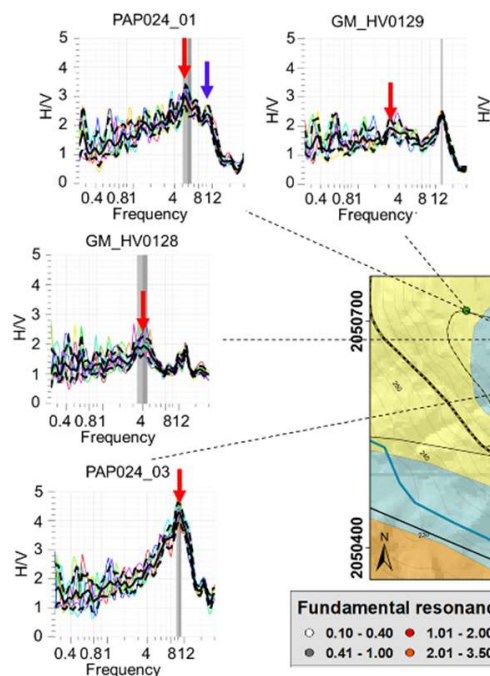

b)
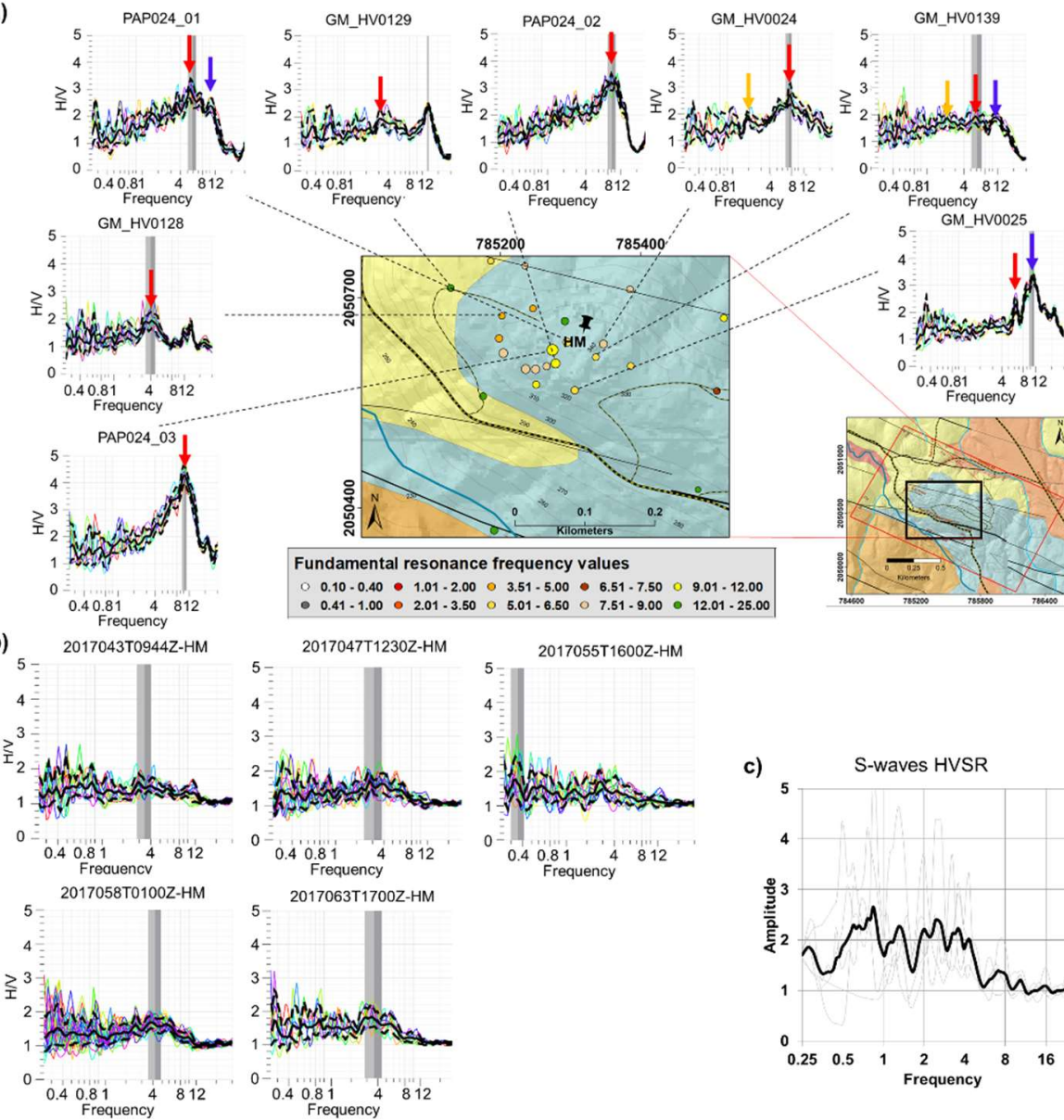

Fundamental resonance frequency values $0.10-0.40 \cdot 1.01 \cdot 2.00 \div 3.51 \cdot 5.00 * 6.51 \cdot 7.50 \circ 9.01 \cdot 12.00$ $0.41 \cdot 1.00 \div 2.01 \cdot 3.50 \div 5.01 \cdot 6.50 \circ 7.51 \cdot 9.00-12.01 \cdot 25.00$

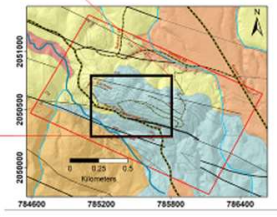

A

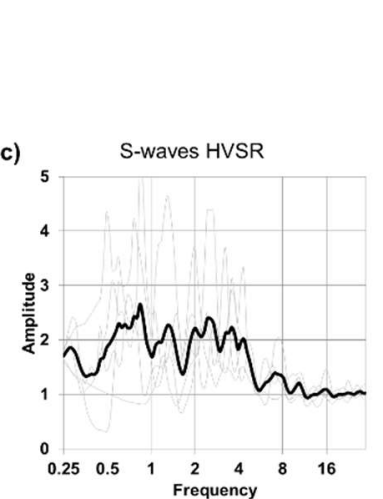

Figure 13. Graphs showing the HVSR curves from different measurements performed at the Hotel Montana with their specific location. The position of the station HM is also indicated. In (a), some ambient noise HVSR curves obtained for Tromino measurements are shown; the red and blue arrows respectively indicate the fundamental and second frequency peaks; the yellow arrow indicates a third peak, which is very slight; in (b), HVSR graphs are shown for noise recordings on station HM. (c) Single (grey curves) and average (black curve) S-waves HVSR are shown for the five selected earthquakes recorded by the station HM (squared average of HVSR computed for E-W and N-S components).

\subsubsection{SSR Results}

The relative flatness of the ambient vibrations HVSR curves at the Delmas 60 and FIC compared to those recorded at Hotel Montana suggests that these stations are only affected by light site amplification. This can be verified by analyzing the Fourier Spectra (FS) for each earthquake at the three stations. The FS of HM are slightly higher than those at FIC station (Figure A1a in the Appendix), but they globally present the same range of amplitude. The Delmas 60 station FS (Figure A1b in the Appendix) are characterized by lesser amplification. However, it is important to note that no outcropping rock has been found near their location; on the contrary, from Figure 4, it can be seen that FIC is located on fan alluvial deposits and Delmas 60 on marly limestone. In addition, although no velocity data were recorded directly at these sites, their velocity values suspected from the interpolated available seismic profiles indicate that soils could be stiffer below HM station. Consequently, FIC and Delmas 60 may not be ideal reference stations, but in the neighborhood of Gros-Morne hill, those were the best places we could find. Below, we will present results using both stations as reference station for station Hotel Montana. When analyzing related results, one has to bear in mind that amplification levels computed for $\mathrm{HM}$ are probably slightly underestimated (due to the aforementioned minor site effects affecting both reference sites: below $2 \mathrm{~Hz}$ for Delmas 60 and above $1.5 \mathrm{~Hz}$ for FIC station). 
a1)
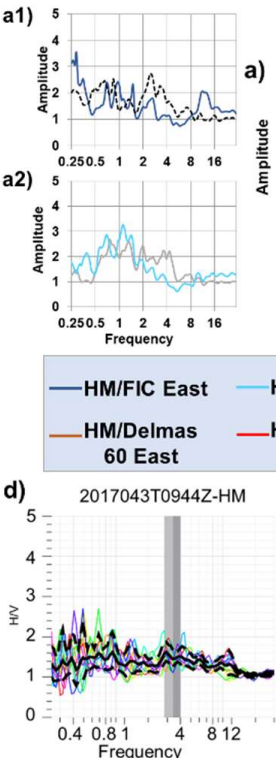

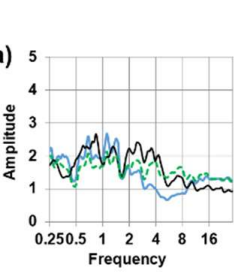

b1) 5
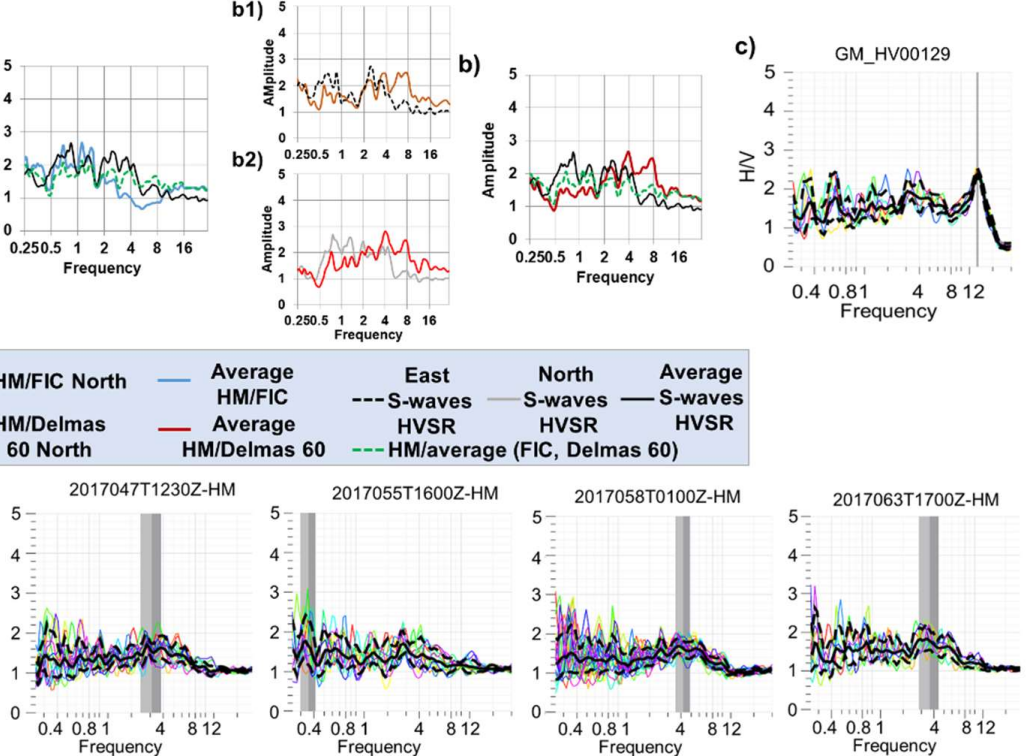

Figure 14. Comparison between the SSR and HVSR results for station HM. (a) SSR computed with respect to FIC station, in (a1) for the E-W component, in (a2) for the N-S component; (b) SSR computed using the Delmas 60 station as reference, in (b1) for the E-W component, in (b2) for the N-S component. In both subfigures (a) and (b), the black curve represents the S-wave HVSR for HM station and the green dashed curve shows the average SSR for HM computed with respect to the averaged FIC-Delmas 60 spectra (combination of two reference stations); see also the dashed curve of E-W S-waves HVSR in (a1) and (b1) and the grey curve of N-S S-waves HVSR in (a2) and (b2). (c) Tromino ambient vibration HVSR near HM station; (d) ambient vibration HVSR computed from recordings at HM station.

SSRs computed for HM-recordings with respect to Delmas 60 and FIC recordings are first determined separately for each horizontal component, east-west and north-south, and for each single earthquake. Then, an (arithmetic) average SSR for the five earthquakes is computed for each horizontal component. Finally, the squared average $\left(\mathrm{H}_{\mathrm{avg}}\right)$ of the horizontal components is calculated. The resulting SSR results are compared with the S-waves HVSR (squared average for both E-W and N-S components) in Figure 14a,b, while the HVSR for the closest Tromino HVSR near HM station are shown in Figure 14c, and HVSR for ambient vibrations measured at HM station are presented in Figure 14d. Figure 14a1,a2 respectively present the E-W and N-S SSR with respect to station FIC. E-W and N-S SSR using Delmas 60 as a reference station are shown in Figure 14b1,b2.

Relatively low amplification factors are outlined by the SSR computed with respect to both reference sites. The highest amplification factors vary between two and three. As for most of the Tromino recordings near Hotel Montana, the peaks observed for the SSR computed with respect to Delmas 60 recordings are around 2-2.5 Hz, $4 \mathrm{~Hz}$ and $7.5 \mathrm{~Hz}$. The S-wave HVSR and the SSR curves are not generally in good agreement. Considering the single components, fits between S-waves HVSR and SSR are only obtained for small frequency ranges. The average S-waves HVSR amplitude level is similar to the one of the SSR computed with respect to both stations. It can also be observed that both the S-waves HVSR and SSR are systematically larger than the ambient noise HVSR.

The SSRs using both reference stations allowed us to confirm the two resonance frequency peaks $(0.5-2 \mathrm{~Hz}$ and around $4 \mathrm{~Hz}$ ) identified from the HVSR measurements. Moreover, for those peaks amplitudes similar to those shown by the HVSR can be observed. The FS amplitudes noticed in the reference stations may imply an underestimation of the SSR frequency peaks. Consequently, it can be inferred that real amplification could be slightly higher than those computed with the SSR method for HM station. 
Above, we have already introduced the identification of possible topographic effects on Gros-Morne hill, as indicated by some ambient noise HVSR amplitudes between 1 and $3 \mathrm{~Hz}$ at or near HM station. In this regard, we would like to point to the different SSR amplitudes obtained for the E-W and N-S components in this frequency range. Especially between 1 and $2 \mathrm{~Hz}$, the N-S SSR show for both reference stations larger amplitudes than the E-W SSR. This could be due to the preferred N-S vibration of the entire roughly W-NW-E-SE-oriented hill, which is thus subparallel to the short axis of the hill. Topographic amplification is generally marked by such a polarization of the wave field, with stronger amplitudes perpendicular to the main axis (i.e., along the shot axis) of the hill or mountain (see, e.g., the overview on topographic effects in [30]).

\section{Discussion}

The high electrical conductivity within the subsurface of the investigated sites hints, in a first approximation, at a low compactness of the soils, at least for the first $13 \mathrm{~m}$ below the surface. The highest resistivity values found at the top of the hill suggest that this part of the hill should be more compact (and/or drier) than elsewhere, whereas the lowest resistivity values measured in the southwestern corner indicate that soils in this area should be less consolidated (and/or wetter). These results from the ERT surveys interpreted in terms of compactness are confirmed by the MASW results, which depict higher and lower shear wave velocity values respectively on the hilltop and in the south and southwestern parts (see Figure 7). Nevertheless, it is important to note that relatively low resistivity values were recorded along the profile ERT02 with regard to the high shear wave velocities measured in the northeastern corner of Gros-Morne, the area of Route de Delmas. ERT02 was carried out near a ravine; its lower values could thus be due to the proximity of the ravine. Following these results, it appears that the Gros-Morne site mostly includes two parts. The first one is a more compact zone with a higher velocity in the range of $600-700 \mathrm{~m} / \mathrm{s}$ along the first $15 \mathrm{~m}$ of depth. It is located on the top of the hill and in the northeastern corner. The second one is an area constituted of less consolidated rocks characterized by low velocity $(<400 \mathrm{~m} / \mathrm{s})$ and low resistivity values. This latter is located along the lower parts of the hill and especially in the southwest, at its base, within the ravine (see also the Vs log of profile SW015 in Figure 7). The northeastern corner is also described by flat HVSR curves denoting no impedance contrast and consequently no susceptibility of site amplification. At the northern base of the hill, the amplitude values are rather low $(\mathrm{A}<2)$ to moderate $(2 \leq \mathrm{A} \leq 3)$ suggesting that the likely site amplification is either negligible or moderate. High amplitude values characterize the western and southwestern base of Gros-Morne. They were recorded at a frequency ranging from $2-25 \mathrm{~Hz}$, but in this study, only those with a resonance frequency below $12 \mathrm{~Hz}$ are considered as relevant for site amplification estimates. The ground along the ridge is marked by very variable resonance frequency and amplitude peak values. Most of the sites preferentially reveal a ground motion resonance at about $6-8 \mathrm{~Hz}$ and $10-12 \mathrm{~Hz}$, but at the $\mathrm{HM}$ station, also lower frequency peaks (around $1-2 \mathrm{~Hz}$ and at $3-4 \mathrm{~Hz}$ ) have been produced by various HVSR and SSR curves. The amplitude values range from 2-4 (see Figures 8, 13 and 14). As amplitude levels of up to 3-4 were found in very few places, we conclude that the higher parts of Gros-Morne can be locally marked by moderate to high amplification, but are globally characterized by moderate site effects. In the lower parts near the western and southwestern foothills, the largest HVSR ratios hinting at a generally high amplification level were observed.

During some of the previous studies, the results obtained concur in the determination of the main amplified frequency ranges, but the amplitude levels and their interpretation are not always consistent with those presented in this paper (a comparison is shown in Figure 15). Results from [5] outlined two main resonance peaks at 2.3 and $6.8 \mathrm{~Hz}$, with respective amplitudes of three and four (Figure 15b) and which they mainly attributed to topographic effects. Assimaki et al. [6] computed much higher amplitudes of about 10-12 for those two frequency ranges (see Figure 15c) using the same dataset and consequently concluded that the Gros-Morne hill crest must be affected by very strong site effects. Moreover, they attributed the 7-Hz peak to a coupling of topographical and stratigraphic 
amplification. To justify their topographical 7-Hz peak, they first assume that the bedrock at the hill is characterized by a shear wave velocity of $2286 \mathrm{~m} / \mathrm{s}$ similar to HCEA station. Second, they considered that the $600 \mathrm{~m}$-wide hill (in the N-S direction) produces an amplification for a wavelength that is half of the hill width, i.e., $300 \mathrm{~m}$. Taking the average Vs $=2286 \mathrm{~m} / \mathrm{s}$ for the hill material, the topographic resonance frequency would then be $2286 / 300 \sim 7.5 \mathrm{~Hz}$. Our low frequency topographical amplification interpretation is rather based on the rule of [28]. The latter argued that for a hill with free slopes to both sides of the crest, the amplified wavelength is similar to the entire width of this hill (actually, the width of the hill is a minimum of $700 \mathrm{~m}$ and not $600 \mathrm{~m}$ ). Here, for Gros-Morne hill, the frequency of topographical amplification should be $\sim 3 \mathrm{~Hz}$ and $\sim 1.8 \mathrm{~Hz}$ for a bedrock velocity of respectively $2286 \mathrm{~m} / \mathrm{s}$ and $1300 \mathrm{~m} / \mathrm{s}$. We observed clearly higher amplitudes between 1 and $2 \mathrm{~Hz}$ on the N-S SSR with respect to the E-W SSR, which are more likely due to topographic effects than what has been assumed by [6], who considered a 7-Hz peak as the one due to topographic amplification (as the hill section has a minimum length of $700 \mathrm{~m}$ and not of $600 \mathrm{~m}$ and as the Vs of the hill rocks at a depth is certainly well below $2000 \mathrm{~m} / \mathrm{s}$ and probably even below $1300 \mathrm{~m} / \mathrm{s}$ ).

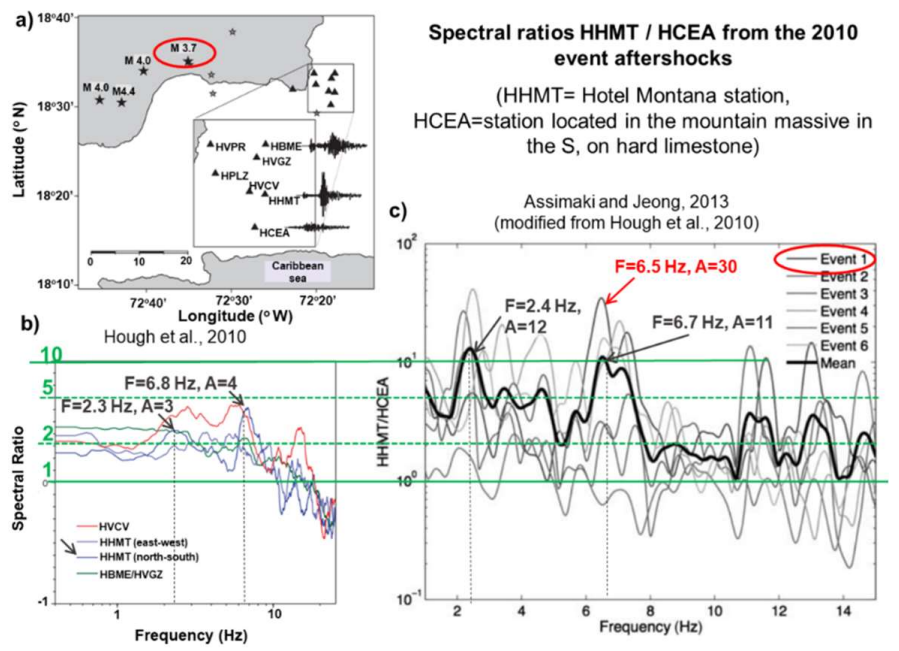

Figure 15. (a) Map of stations and recorded aftershocks (from [6]); (b) spectral ratios for several sites inside and near Port-au-Prince, using HCEA station (located in the "Massif de la Selle"; see also the map in Figure 3a, in the Introduction) as a reference, presented by Hough et al. (2010) on the basis of recorded aftershocks of the 12 January 2010, event. The spectral ratios for Hotel Montana (HHMT) with respect to HCEA are shown by the violet lines. The dark violet line shows the spectral ratio for the N-S component ( perpendicular to ridge orientation), with the indication of frequencies (F) and amplitudes (A) of the two main peaks that can be observed below $10 \mathrm{~Hz}$. (c) Spectral ratios obtained for the same dataset by [6] for Hotel Montana. Several amplification levels are marked by green lines.

The main reason for our lower computed spectral ratios, compared to these previous studies (especially with respect to the results of [6], is probably related to the selection of the reference site. Both studies were carried out considering HCEA as the reference station. This site located on hard pelagic limestone is characterized by a bedrock velocity of $2286 \mathrm{~m} / \mathrm{s}$ as measured by [29]. On a geological section presented in [7], it can be clearly seen that below Gros-Morne hill, there are no such hard pelagic limestones (at least not within a depth of less than $200 \mathrm{~m}$, i.e., inside the hill) as those found under station HCEA. Additionally, during our geophysical surveys, we did not find any outcrops with such limestone near Gros-Morne. Thus, the amplitude calculations using HCEA as the reference station may have overestimated the amplification level. [7] already hinted at a possible overestimation of the amplification levels if only HCEA is used as the reference station. The spectral ratios of [7] also produced peaks at around 2-2.5 and $7 \mathrm{~Hz}$, but with amplitudes lower than or equal to three. As shown above and reproduced in Figure 16 below for comparison, our spectral ratios using 
Delmas 60 as the reference station, as well as S-wave HVSR obtained for the Hotel Montana site also present peaks at similar frequencies with slightly smaller amplitudes. However, as indicated above, the local conditions of FIC and Delmas 60, marked by the presence near the surface of relatively soft marly-limestone, clay, calcareous silt conglomerates and a Pliocene conglomeratic unit, certainly also implies slight local amplification at these sites that we used as a reference. This was confirmed by the Fourier spectra of each component. Spectral ratios computed with respect to these two stations probably thus underestimate local amplification levels.

a)

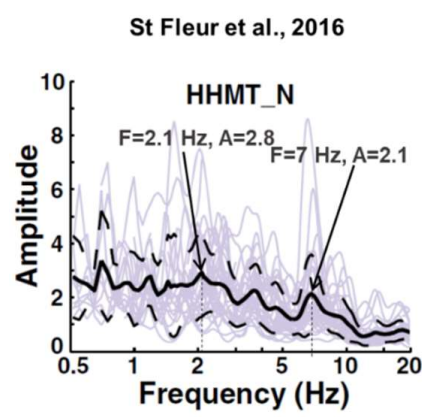

b) This paper: using Station Delmas 60 as reference

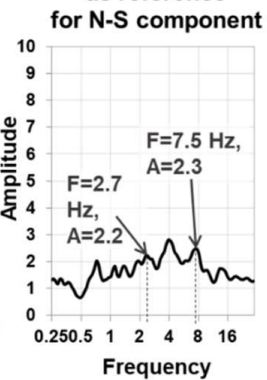

c) This paper :

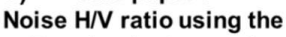
Tromino instrument

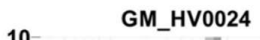

10

8

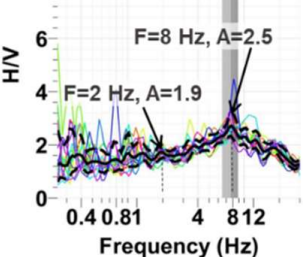

Figure 16. (a) Spectral ratios for Hotel Montana site (HHMT), using both HCEA and PAPH stations (HCEA is located in the "Massif de la Selle"; PAPH is located near Pétion-Ville, at about $400 \mathrm{~m}$ south of HHMT; see the map in Figure 3a, in the Introduction) as the combined reference, presented by [7] on the basis of recorded aftershocks (N-S component) of the 12 January 2010, event, with the indication of the frequencies (F) and amplitudes (A) of the two main peaks that can be observed between 1 and $10 \mathrm{~Hz}$. (b) Spectral ratios obtained for our earthquake dataset for Hotel Montana (N-S component), using Delmas 60 as the reference station; (c) HVSR curve obtained for the same site. Several amplification levels are marked by green lines (for comparison between various results).

Here, we will not further discuss the validity of our results with respect to previous measurements and to observed damage distributions. Some (simple) comparison with the latter will be provided in a follow-up paper by the same authors ([31]); this comparison will be supported by additional overview maps of interpolated HVSR results, a 3D geomodel of Gros-Morne hill and a 2D numerical analysis of site effects for a central cross-section of the hill. In this paper, we mainly wanted to highlight the fact that a hill structure can be affected by multiple types of site effects that can vary over relatively short distances (over less than $200 \mathrm{~m}$ ). Some topographic effects have been identified, but need to be confirmed by the numerical modelling results.

\section{Conclusions}

From the results produced by some previous surveys and combined with ours, we can infer that the top of Gros-Morne hill, including also the Hotel Montana area, does not really suffer from severe local amplification effects. Very strong amplification on the hill could only be observed during previous studies that used as a reference a hard rock site located in the mountain massif in the south of Port-au-Prince; and it could only be shown for specific events. Such a hard rock can probably not be found directly under the hill and, therefore, cannot be taken as the reference for site effect studies. However, also the "ineptitude" of the former hard (and also of our soft) reference site does not explain why, for some aftershock events in 2010, previous studies determined spectral ratios with amplitudes higher than 10-20, which are several times larger than our computed maximum amplification levels between 0.5 and $10 \mathrm{~Hz}$ (of about 2-3). We, therefore, argue that the very large ground motions observed for some events on Gros-Morne hill, in comparison with those measured at the hard rock site in the mountains, can only be explained by coupled source-path-site effects. Additionally, such effects cannot be easily reproduced by $1 \mathrm{D}$ or 2D models. They can only be assessed using combined regional and 
local 3D dynamic models; and in cases similar to the one of Gros-Morne hill, probably only such integrated 3D models could help make ground motion and related damage distribution patterns more predictable.

Acknowledgments: This work was carried out thanks to the financial support of the Belgian "Académie de Recherche et d'Enseignement Supérieur (ARES)". It was done in the framework of a PhD thesis that was part of the Belgian-Haitian collaboration project funded by ARES. We thank the team of the Research Unit of Geosciences of the Faculty of Sciences of Haiti State University for their support and collaboration, as well as the team of the Technical Unit of Seismology, which helped us collect the seismological data. We further thank the former General Director of the Bureau of Mining and Energy, Ludner Remarais, for his support, Jean-Marie Saurel from the Volcanological and Seismological Observatory of Martinique for his support in the identification of the earthquakes, as well as Phillipe Cerfontaine from the Georisk and Environment team of the University of Liege for his assistance. Our thanks also go to all those who have accepted to host the seismological stations: Von Lignau, from the Hotel El Rancho, the brothers of Christian Instruction, the Hotel Montana and Muller.

Author Contributions: The research work has been completed by the main author, Sophia Ulysse, who also carried out most of the field measurements and data analyses. Both co-authors Dominique Boisson and Claude Prépetit have provided essential mapping and report inputs and have supervised the field measurements. The data analysis has been supervised by co-author Hans-Balder Havenith. The manuscript has been prepared in close collaboration between Sophia Ulysse and Hans-Balder Havenith, and was corrected by the two other co-authors.

Conflicts of Interest: The authors declare no conflicts of interest.

\section{Appendix Appendix}

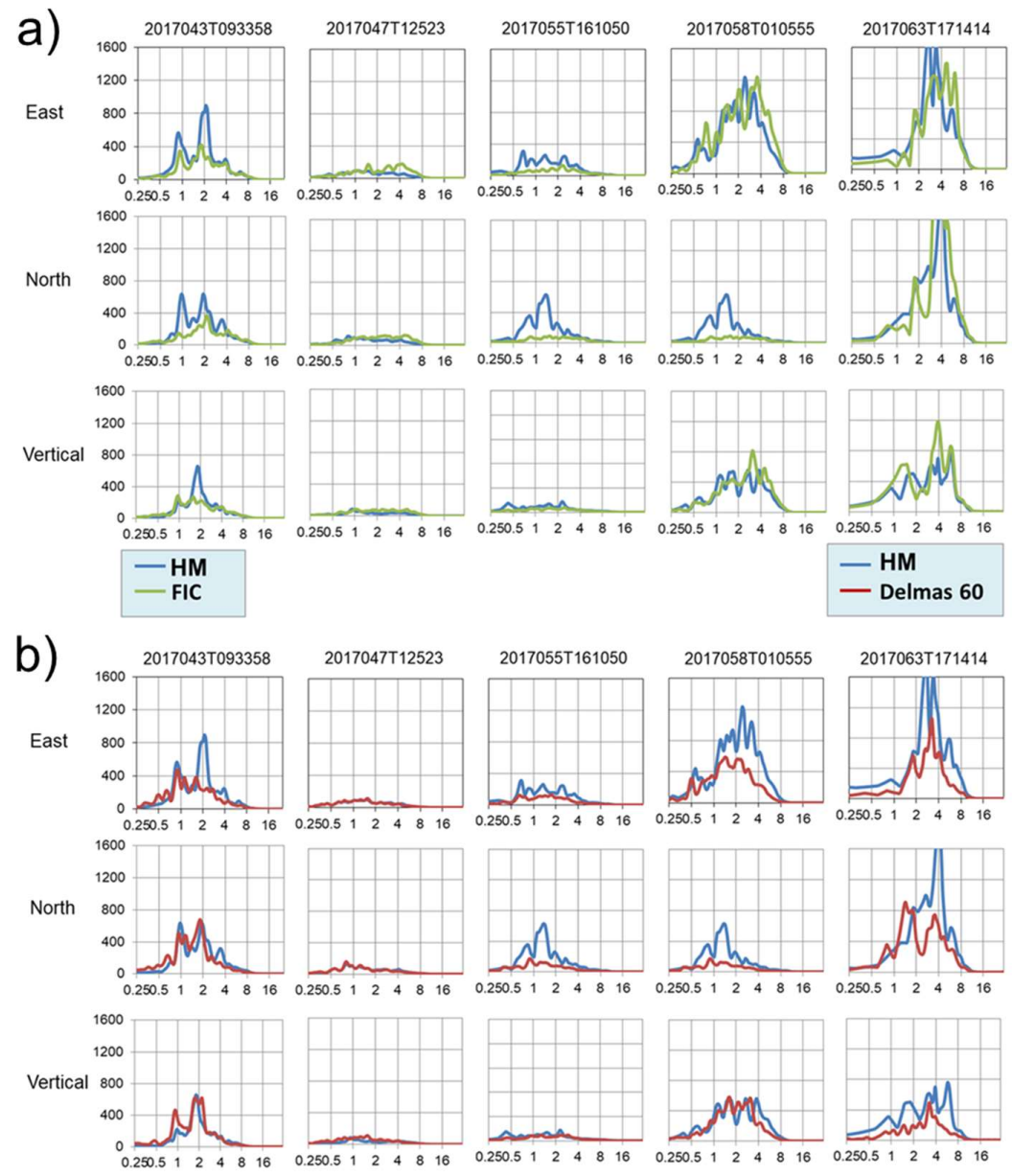

Figure A1. (a) Comparison between the Fourier spectrum of station HM and station FIC; (b) Comparison between the Fourier spectrum of station HM and station Delmas 60. In the horizontal axis is shown the frequency values, and the amplitudes are represented in the vertical axis. 


\section{References}

1. Frankel, A.; Harmsen, S.; Mueller, C.; Calais, E.; Haase, J. Seismic hazard maps for Haiti. Earthq. Spectra 2011, 27 (Suppl. 1), 23-41. [CrossRef]

2. Shedlock, K.M.; Tanner, J.G. Seismic hazard map of the western hemisphere. Ann. Geofis. 1999, 42, 1199-1214.

3. Symithe, S.; Calais, E. Present-day shortening in Southern Haiti from GPS measurements and implications for seismic hazard. Tectonophysics 2016, 679, 117-124. [CrossRef]

4. Bilham, R. Lessons from the Haiti earthquake. Nature 2010, 463, 878-879. [CrossRef] [PubMed]

5. Hough, S.E.; Altidor, J.R.; Anglade, D.; Given, D.; Janvier, M.G.; Maharrey, J.Z.; Meremonte, M.; Mildor, B.S.-L.; Prepetit, C.; Yong, A. Localized damage caused by topographic amplification during the 2010 M7.0 Haiti earthquake. Nat. Geosci. 2010, 3, 778-782. [CrossRef]

6. Assimaki, D.; Jeong, S. Ground-motion observations at Hotel Montana during the M 7.0 2010 Haiti earthquake: Topography or soil amplification? Bull. Seismol. Soc. Am. 2013, 103, 2577-2590. [CrossRef]

7. Saint-Fleur, S.; Bertrand, E.; Courboulex, F.; De Lépinay, B.M.; Deschamps, A.; Hough, S.; Cultrera, G.; Boisson, D.; Prépetit, C. Site effects in Port-au-Prince (Haiti) from the analysis of spectral ratio and numerical simulations. Bull. Seismol. Soc. Am. 2016, 106, 1298-1315. [CrossRef]

8. Grelle, G.; Wood, C.; Bonito, L.; Sappa, G.; Reveillino, P.; Rahimi, S.; Guadagno, F.M. A reliable computerized litho-morphometric model for development of 3D maps of Topographic Aggravation Factor (TAF): The cases of East Mountain (Utah, USA) and Port-au-Prince (Haiti). Bull. Earthq. Eng. 2017. [CrossRef]

9. Calais, E.; Freed, A.; Mattioli, G.; Amelung, F.; Jónsson, S.; Jansma, P.; Hong, S.-H.; Dixon, T.; Prépetit, C.; Momplaisir, R. Transpressional rupture of an unmapped fault during the 2010 Haiti earthquake. Nat. Geosci. 2010, 3, 794-799. [CrossRef]

10. Terrier, M.; Bialkowski, A.; Nachbaur, A.; Prépetit, C.; Joseph, Y.F. Revision of the geological context of the Port-au-Prince metropolitan area, Haiti: Implications for slope failures and seismic hazard assessment. Nat. Hazards Earth Syst. Sci. 2014, 14, 2577-2587. [CrossRef]

11. Butterlin, J. Géologie Générale de la République d'Haïti; Travaux et Mémoires; Institut des Hautes Études de l'Amérique Latine: Paris, France, 1960; Volume 6, p. 194.

12. Bourgueil, B.; Andreieff, P.; Lasnier, J.; Gonnard, R.; Le Métour, J.; Rançon, J.-P. Synthèse Géologique de la République d'Haïti: Volume I-Géologie; ATN/SF 2506 HA; Bureau Des Mines et de l'Énergie: Port-au-Prince, Haïti, 1988; Volume 1, p. 332.

13. Boisson, D.; Momplaisir, R.B.-A. Carte Géologique d'Haïti, 1/250000ème; Bureau des Mines et de l’Energie: Port-au-Prince, Haïti, 1988.

14. Bachhuber, J.L.; Rathje, E.M.; Cox, B.R.; Kottke, A.; Wood, C.; Dulberg, R.A.; GEER Team. Haiti Geologic UNOSAT Damage Map; GEER Team: Port-au-Prince, Haiti, 2010.

15. Ministry of Agriculture Water Resources and Rural Development. Ministère de l'Agriculture des Ressources Naturelles et du Développement Rural. Service des Ressources en Eau; Carte Hyrogéologique de la République d'Haïti. Echelle 1/250000; 1990.

16. Galli, P.A.C.; Giocoli, A.; Peronace, E.; Piscitelli, S.; Quadrio, B.; Bellanova, J. Integrated near surface geophysics across the active Mount Marzano Fault System (southern Italy): Seismogenic hints. Int. J. Earth Sci. 2014, 103, 315-325. [CrossRef]

17. Nogoshi, M.; Igarashi, T. On the propagation characteristics ofmicrotremor. J. Seismol. Soc. Jpn. 1970, 23, 264-280.

18. Nakamura, Y.A. Method for Dynamic Characteristics Estimation of Subsurface Using Microtremor on the Ground Surface; Quarterly Report; Railway Technical Research Institute: Tokyo, Japan, 1989; Volume 30, pp. $25-33$.

19. Bonnefoy-Claudet, S.; Cornou, C.; Bard, P.Y.; Cotton, F.; Moczo, P.; Kristek, J.; Fäh, D. H/V ratio: A tool for site effects evaluation. Results from 1-D noise simulations. Geophys. J. Int. 2006, 167, 827-837. [CrossRef]

20. Lachet, C.; Bard, P.Y. Numerical and Theoretical Investigations on the Possibilities and Limitations of Nakamura's Technique. J. Phys. Earth 1994, 42, 377-397. [CrossRef]

21. Borcherdt, R.D. Effects of local geological geology on ground motion near the San Francisco. Bull. Seismol. Soc. Am. 1970, 60, 29-61. 
22. Laurendeau, A.; Courboulex, F.; Bonilla, L.F.; Alvarado, A.; Naya, V.A.; Guéguen, P.; Mercerat, E.D.; Singaucho, J.C.; Bertrand, E.; Perrault, M.; et al. Low-Frequency Seismic Amplification in the Quito Basin (Ecuador) Revealed by Accelerometric Recordings of the RENAC Network. Bull. Seismol. Soc. Am. 2017, 107, 2917-2926. [CrossRef]

23. Loke, M.H. Tutorial: 2-D and 3-D Electrical Imaging Survey. 2011. Available online: https:/ / pangea.stanford. edu/research/groups/sfmf/docs/DCResistivity_Notes.pdf (accessed on 20 April 2018).

24. Wathelet, M. GEOPSY Geophysical Signal Database for Noise Array Processing. Software, LGIT, Grenoble. 2005. Available online: www.geopsy.org (accessed on 20 April 2018).

25. Konno, K.; Ohmachi, T. Ground-Motion Characteristics Estimated from Spectral Ratio between Horizontal and Vertical Components of Microtremor. Bull. Seismol. Soc. Am. 1998, 88, 228-241.

26. Bard, P.; the SESAME-Team. Guidelines for the Implementation of the H/V Spectral Ratio Technique on Ambient Vibrations: Measurements, Processing, and Interpretations, SESAME European Research Project Report: European Commission-Research General Directorate Project No. EVG1-CT-2000-00026 SESAME, 2004; p. 62. Available online: ftp:/ / ftp.geo.uib.no/pub/seismo/SOFTWARE/SESAME/USER-GUIDELINES/ SESAME-HV-User-Guidelines.pdf (accessed on 20 April 2018).

27. Soutmans, T. Application de la Méthode Microsismique H/V Aux Études de Sites de Stockage de Déchets à LUBUMBASHI (République Démocratique du Congo) et de Glissements de Terrain Dans la Vallée de Maily-Say (République du Kirghizistan). Master Thesis, University of Liege, Liège, Belgium, 2010; p. 110.

28. Geli, L.; Bard, P.Y.; Jullien, B. The effect of topography on earthquake ground motion: A review and new results. Bull. Seismol. Soc. Am. 1988, 78, 42-63.

29. Cox, B.R.; Bachhuber, J.; Rathje, E.; Wood, C.M.; Dulberg, R.; Kottke, A.; Olson, S.M. Shear wave velocity-and geology-based seismic microzonation of Port-au-Prince, Haiti. Earthq. Spectra 2011, 27, 67-92. [CrossRef]

30. Massa, M.; Barani, S.; Lovati, S. Overview of topographic effects based on experimental observations: Meaning, causes and possible interpretations. Geophys. J. Int. 2014, 197, 1537-1550. [CrossRef]

31. Ulysse, S.; Boisson, D.; Prépetit, C.; Havenith, H.B. Site Effect Assessment of the Gros-Morne Hill Area in Port-au-Prince, Hait, Part B: Mapping and Modelling Results. Geosciences 2018, in press.

(C) 2018 by the authors. Licensee MDPI, Basel, Switzerland. This article is an open access article distributed under the terms and conditions of the Creative Commons Attribution (CC BY) license (http:/ / creativecommons.org/licenses/by/4.0/). 